\title{
Current and Future Drug Targets in Weight Management
}

\author{
Renger F. Witkamp
}

Received: 25 August 2010 / Accepted: 29 November 2010 / Published online: 23 December 2010

(C) The Author(s) 2010. This article is published with open access at Springerlink.com

\begin{abstract}
Obesity will continue to be one of the leading causes of chronic disease unless the ongoing rise in the prevalence of this condition is reversed. Accumulating morbidity figures and a shortage of effective drugs have generated substantial research activity with several molecular targets being investigated. However, pharmacological modulation of body weight is extremely complex, since it is essentially a battle against one of the strongest human instincts and highly efficient mechanisms of energy uptake and storage. This review provides an overview of the different molecular strategies intended to lower body weight or adipose tissue mass. Weight-loss drugs in development include molecules intended to reduce the absorption of lipids from the $\mathrm{Gl}$ tract, various ways to limit food intake, and compounds that increase energy expenditure or reduce adipose tissue size. A number of new preparations, including combinations of the existing drugs topiramate plus phentermine, bupropion plus naltrexone, and the selective $5-\mathrm{HT}_{2} \mathrm{C}$ agonist lorcaserin have recently been filed for approval. Behind these leading candidates are several other potentially promising compounds and combinations currently undergoing phase II and III testing. Some interesting targets further on the horizon are also discussed.
\end{abstract}

KEY WORDS energy metabolism · food-intake · obesity complications · satiety hormones · weight management

R. F. Witkamp $(\square)$

Division of Human Nutrition

Wageningen University

P.O. Box 8129, 6700 EV Wageningen, The Netherlands

e-mail: renger.witkamp@wur.nl

\section{ABBREVIATIONS}

$5-\mathrm{HT}$

| $|\beta-H S D|$

$\mathrm{AgRP}$

B3AR

BAT

BMI

CART

$\mathrm{CBI}$

CCK

CNS

DGAT

DPP-IV

EEC

GABA

$\mathrm{GH}$

Gl

GLP- I

HPA(-axis)

$\mathrm{MCH}$

MGAT

$\mathrm{MSH}$

MTP

NPY

OXM

POMC

PP

PPAR Y

PYY

SGLT2

TRPV type I serotonin (5-hydroxytryptamine)

I I- $\beta$ hydroxysteroid dehydrogenase type | agouti-related protein

$\beta_{3}$-adrenoceptors

brown adipose tissue body mass index cocaine-amphetamine-regulated transcript cannabinoid receptor type I cholecystokinin central nervous system diacylglycerol O-acyltransferase dipeptidyl peptidase IV entero-endocrine cell gamma-amino butyrate growth hormone gastro-intestinal glucagon-like peptide I hypothalamic-pituitary-adrenal (-axis) melanine-concentrating hormone 2-acylglycerol O-acyltransferase melanocyte-stimulating hormone microsomal triglyceride transfer protein neuropeptide $Y$ oxyntomodulin pro-opiomelanocortin pancreatic polypeptide peroxisome proliferator-activated receptor- $Y$ peptide $Y Y$

(low affinity) sodium-dependent glucose co-transporter

transient receptor potential cation channel $\mathrm{V}$ type I 


\section{INTRODUCTION-HEALTH RISKS OF BODY FAT}

Obesity has become a serious and worldwide public health problem with important consequences for healthcare costs $(1-3)$. The common way to classify obesity is by body mass index (BMI), which is calculated as weight in $\mathrm{kg} / \mathrm{height}$ in meters squared. Persons with a BMI over 25 are called overweight, whereas a BMI of over 30 represents obesity. Both classifications are major risk factors for a cluster of health complications often referred to as the metabolic syndrome $(1,4,5)$. These include (pre-)diabetes type 2, hypertension and other cardiovascular complications. In addition, obesity leads to an elevated risk for developing other diseases, such as non-alcoholic fatty liver disease, osteoarthritis, sleep apnea, cognitive decline and certain forms of cancer (6). Although BMI remains a useful general indicator for health risk, particularly at a population level, it has become clear that health complications are largely dependent on the localization and activity of the different fat depots. For any given amount of total body fat, those individuals with a predominant excess of intra-abdominal or visceral adipose tissue are at substantially higher risk of becoming insulin resistant or getting any of the other features of the metabolic syndrome $(4,7,8)$. Therefore, waist circumference or waist/hip ratio is often a better indicator than BMI (9,10). Furthermore, there remains a risk of under diagnosis, since persons who look "thin outside" but have relatively much fat "hidden" within organs, such as muscles, heart and liver ("fat inside"), bear considerable health risks $(11,12)$. Within fat tissue, the adipocyte phenotypes and infiltration of immune cells are considered pivotal determinants for the development of metabolic complications $(13,14)$. It has been shown that adipose tissue can initiate and maintain a low-grade inflammatory process, which in turn activates inflammatory responses in liver and other organs. Another important risk factor is the presence of high levels of free fatty acids in plasma $(15,16)$.

Taken together, it is understandable that the problem of adiposity has boosted considerable activity in pharmaceutical development, which is often going far beyond achieving or maintaining a healthy body weight only. Fig. 1 illustrates the great diversity in potential targets.

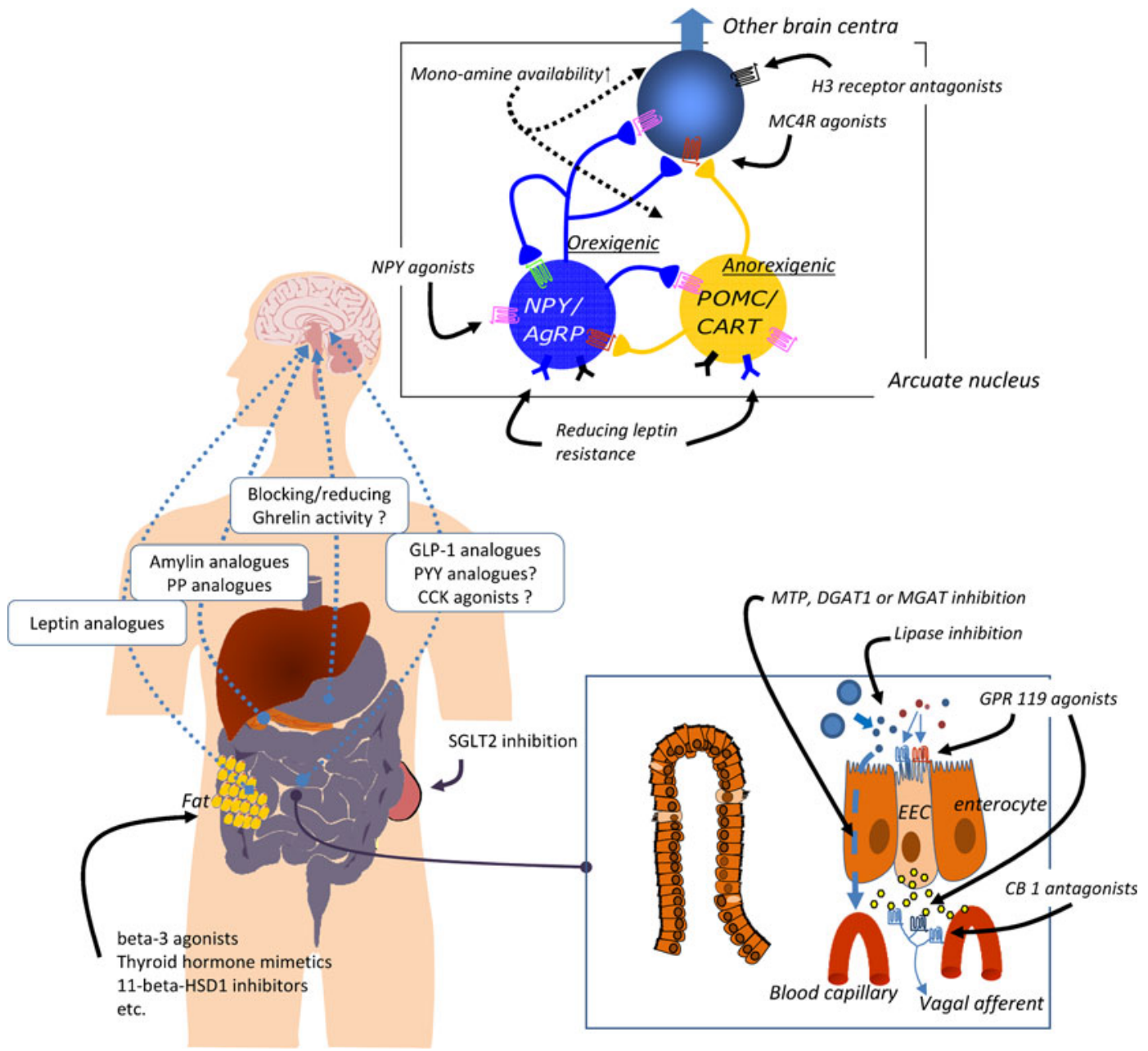

Fig. I Schematic representation of potential strategies and targets as discussed in this review, to reduce food intake, body weight or adipose tissue mass. 
In Table I, the potential approaches have been categorized into the most important areas of research and development.

Basically, the first three categories primarily target body weight, which is the focus of this review. However, there is not always a sharp division between reduction of weight or reduction of complications as primary goal, while combining these objectives also offers advantages. Specifically modulating metabolic or immunological processes associated with adiposity is considered potentially effective to reduce health complications. An interesting example is the approach to reduce the pro-inflammatory state in overweight and obese persons using anti-inflammatory compounds such as salsalate (17-19). In addition, strategies aiming to modulate body fat distribution and not primarily total body fat are being investigated. This is based on the observation that persons with a predominant android ("apple") body shape are at higher risk for cardiovascular disease than persons having a more gynaeoid ("pear") body shape. Obviously, genetic and hormonal factors play a role $(20,21)$. Furthermore, fat cell size may be of importance (22). Finally, the discovery that regular physical exercise significantly reduces health risks even in the absence of direct weight reduction $(1,23-25)$ has stimulated the research on an "exercise pill" (24,26-28).

\section{WEIGHT MANAGEMENT DRUGS-ISSUES AND NEEDS}

While keeping in mind that health risks are not simply determined by body weight or even total body fat mass, losing weight is still commonly regarded as effective in overweight people who are developing symptoms of the (pre-)metabolic syndrome. Ideally, weight management should be based on lifestyle modification, including the reduction of caloric intake, increased activity, and physical exercise. Unfortunately, long-term effects of diet or exercise on weight are often disappointing. The desire to eat is one of the strongest instincts, and humans have developed powerful mechanisms to guard against starvation during

Table I General Pharmacological Strategies to Combat Overweight or Complications of Adiposity

- Reducing energy absorption from the GI tract or peripheral tissues

- Decreasing food consumption by increasing satiety or satiation, reducing appetite, increasing feelings of reward, etc.

- Reducing body fat by stimulating energy expenditure or inhibiting energy supply of adipose tissue

- Reducing inflammatory activity of adipose tissues

- Modulating body fat distribution, energy fluxes or mimicking physical exercise periods of food scarcity. Our brains do not only generate sensations of hunger as a result of direct metabolic stimulation. Instead, human eating behavior is a combination of liking (hedonic impact), wanting (incentive motivation), and learning (associations and predictions) (29-31). Non-homeostatic overeating is regulated by central dopaminergic, serotonergic, opioid and cannabinoid systems that show many interconnections and overlaps with other important regulatory pathways $(32,33)$. As a result, the development of effective drugs with acceptable sideeffects can be very cumbersome. With respect to durable weight reduction, bariatric surgery is the most effective long-term treatment for severe obesity with the greatest chances for amelioration and even resolution of obesityassociated complications, including diabetes $(34,35)$. However, depending on the technique used, it is not without surgical risks or metabolic complications (35) and involves high costs. Pharmacological options are to be considered as an adjunct to dietary measures and physical exercise, and long-term weight management by drug treatment alone does not seem realistic at present. However, there will be situations where the use of drugs or possibly even vaccines to reduce weight is medically rational and justified. Criteria for FDA approval of anti-obesity drugs prescribe that $35 \%$ of treated persons must lose at least $5 \%$ of their body weight, and that group should include at least twice as many individuals as the number of patients who achieve a similar weight loss on placebo. Alternatively, the therapy must result in at least 5\% placebo-corrected weight loss. On a population level, such figures will contribute to a lower incidence of complications. The history of development and application of weight loss drugs has shown to be troublesome and characterized by many failures and withdrawals. The most recent example of this occurred in January 2010, when subitramine was suspended from the European market by EMA (www.ema.europe.eu) because of potential cardiovascular risks in certain patients. The compound has remained available in the US, but the FDA issued a safety notification and requested a new contraindication stating that sibutramine should not be used in patients with a history of cardiovascular disease. Another recent case was the suspension of the cannabinoid receptor type 1 (CB1) inverse agonist rimonabant from the EU market in October 2008. At that time, FDA had not given approval for the compound because of doubts regarding its CNS risk-benefit profile. While preparing this review (October 2010) the FDA raised serious concerns on the new applications for lorcaserin and the new phentermine/topiramate combination. In 1997, fenfluramine and dexfenfluramine, particularly popular with phentermine in fen-phen combinations, were withdrawn after reports of negative effects on heart valves and primary pulmonary hypertension (36). The historical list of failures and withdrawals further continues 
with thyroid preparations, ephedrine, dinitrophenol, etc. Despite many efforts to bring new compounds to the market, the intestinal lipase inhibitor orlistat has remained the only compound that is currently approved both in the US and in Europe. However, some new drugs appear to be close to approval, and it is obvious that the pharmacology of weight management remains a highly challenging area for industry and academia. It also represents a multi-billiondollar market, and several research groups are heavily engaged in finding new targets and molecules. The history of discovery of anti-obesity drugs is also characterized by much serendipity. As described further, some of the most advanced preparations currently in the pipeline are based on compounds or drug targets that were originally found for other indications.

\section{STRATEGIES TO REDUCE ENERGY (RE-)ABSORPTION}

Reducing the uptake of energy-rich molecules from the GI tract, preferably by locally acting compounds, could be an attractive approach, since this would minimize the risks of systemic side-effects. Indeed, the lipase inhibitor orlistat belongs to the very few compounds having survived so far. This is also a suggested mechanism of action of many food supplements advertised for weight management. Several of these preparations claim to bind fat in the GI tract, including chitosan, glucomannan, psyllium seeds, etc. However, there seems to be little evidence for sustained efficacy in humans of these products (37). A new lipase inhibitor, cetilistat, is now in an advanced stage of development. In addition, a number of new targets are evolving, including inhibitors of Microsomal Triglyceride transfer Protein (MTP) and Diacylglycerol Oacyltransferase (DGAT). A related but different category comprises the inhibitors of low-affinity sodium-dependent glucose co-transporters (SGLT2). Acting by blocking glucose re-absorption in the kidneys and originally developed for diabetes, some are now in trials for obesity. Farther on the horizon are strategies aiming to modulate GI metabolism.

\section{Inhibitors of Pancreatic Lipase}

Pancreatic lipase is one of the exocrine enzymes of pancreatic juice and is essential for digestion and absorption of dietary fats. Orlistat (Fig. 2) is the tetrahydro-derivative of the natural compound lipstatin, produced by the microorganism Streptomyces toxytricini (38). Orlistat has shown to be effective in reducing body weight, leading to $5-10 \%$ weight loss in $50-60 \%$ of patients. In clinical trials, this loss (and related clinical benefits) has shown to be maintained up to at least four years. A typical side effect of the compound is steatorrhoea (fecal fat loss). The compound is also sold in an OTC preparation in a lower dose compared to the prescription form. Recently, concerns have been raised concerning potential liver damage in orlistat users. In August 2009, the FDA posted an early communication about an ongoing safety review on orlistat (39).

Cetilistat (= ATL-962, Fig. 2) is a newly developed lipase inhibitor which has recently entered phase III clinical testing. It has been suggested that the compound is equally effective as orlistat while producing fewer GI side effects

Fig. 2 Chemical structures of the lipase inhibitors orlistat (an approved drug) and cetilistat (currently in development).

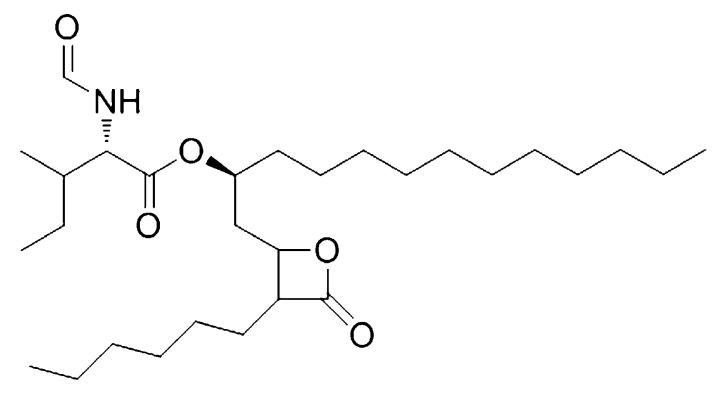

orlistat

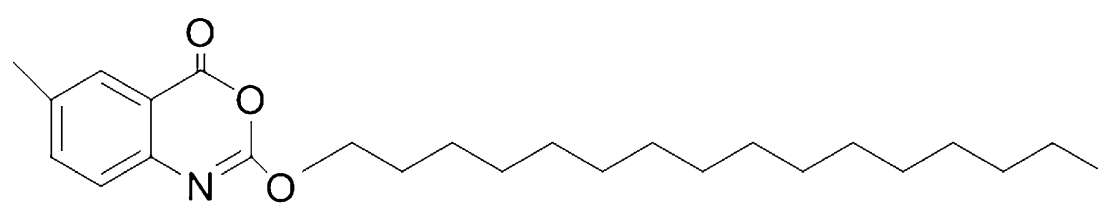

cetilistat (ATL-962) 
(40). However, more long-term studies on the side effects and efficacy of cetilistat are required in order to confirm this and to answer the question whether GI side effects, such as steatorrhoea, are inevitably connected to the mechanism of action of this class. Another lipase inhibitor, called GT 389-255, was under development by Peptimmune, under a license from Genzyme. It was designed as a combination of an (undisclosed) lipase inhibitor and a polymer aiming to bind undigested triglycerides. This should allow increased fat excretion without the side effects of conventional lipase inhibitors. However, the development seems to be stalled or stopped, as there were no further clinical studies reported since the phase I trials conducted in 2004.

\section{Inhibitors of Intestinal Microsomal Triglyceride Transfer Protein (MTP)}

Microsomal triglyceride transfer protein (MTP) is an essential chaperone for the assembly of apolipoprotein B (apoB) (see (41) for recent review). The clinical utility of small-molecule MTP inhibitors to reduce plasma lipids was originally held up by their potential to induce hepatic steatosis, caused by inhibition of the hepatic form of MTP. However, further research led to the discovery of gut selective MTP inhibitors, which predominantly act on the enterocytic form of MTP. This was achieved by compounds that are poorly absorbed or extensively metabolized to inactive metabolites (such as JNJ-16269110). A number of compounds have resulted from this development, but at this stage, their therapeutic potential is not yet clear. The company Aegerion is currently developing EGR-773, lomitapide (previously BMS-201038, Fig. 3) for the treatment of familial hypercholesterolemia, but apparently not for obesity. Pfizer stopped the development of their molecule dirlotapide (Fig. 3) for human use and subsequently launched it in 2007 as the first drug approved for weight management in dogs. Surface Logix (http://www.surfacelogix.com) is currently working on SLx-4090 (structure not disclosed) for various indications, apparently including weight loss. The compound is presently in phase II. Johnson and Johnson recently reported a trial with their new MTP inhibitor JNJ-16269110 in 321 non-diabetic obese subjects. A dose-dependent weight loss of approximately 1.5$3.5 \%$ (corrected for placebo) was obtained after 12 weeks of treatment (42). No significant side effects were reported, and treatment apparently did not lead to unpleasant fecal fat loss.

\section{DGATI and MGAT Inhibitors}

Diacylglycerol O-acyltransferase (DGAT; EC 2.3.1.20) catalyzes the last step of triacylgycerol synthesis. See (43) and (44) for
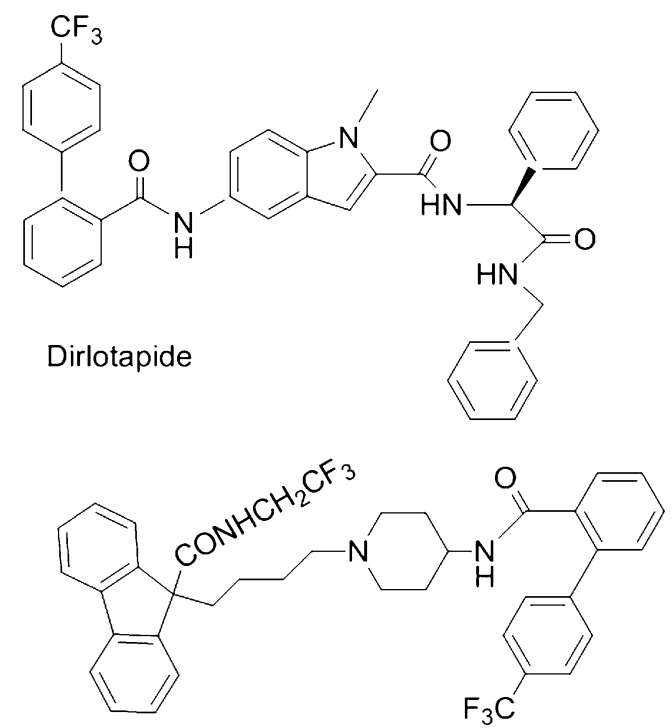

Lomitapide (EGR-773, BMS-201038)

Fig. 3 Chemical structures of two representative MTP inhibitors: dirlotapide and lomitapide.

reviews. DGAT is expressed in different tissues, including liver and white adipose tissue. Two isozymes of DGAT, DGAT1 and DGAT2, have been described so far (http://www.uniprot.org/uniprot). Increased DGAT2 activity has a role in steatosis, while DGAT1 plays a role in VLDL assembly. Increased plasma VLDL concentrations may promote obesity; thus, DGAT1 is considered a potential therapeutic target for obesity control. Pfizer recently (2010) finalized a phase I trial (Clintrial.gov NGT01064492) with their DGATl inhibitor PF 04620110 that is initially being developed for the treatment of type 2 diabetes mellitus. The company anticipates that the compound will have anti-diabetic effects through inhibition of intestinal triglyceride absorption and will potentially cause weight loss. AstraZeneca (www.astrazeneca.com) also report a DGAT1 inhibitor in development for diabetes/obesity in their July 2010 pipeline overview (45).

MGAT (MOGT 2; 2-acylglycerol O-acyltransferase 2; EC 2.3.1.22) catalyzes the formation of diacylglycerol from 2-monoacylglycerol and fatty acyl-CoA. It belongs to the diacylglycerol acyltransferase family $(43,44)$. It is highly expressed in liver, small intestine, colon, stomach and kidney and plays a central role in absorption of dietary fat in the small intestine by catalyzing the re-synthesis of triacylglycerol in enterocytes. It is considered a potential target for weight loss, although concern has been raised because of the theoretical accumulation of fatty acids and monoacylglycerol in enterocytes. Probably due to this, MGAT gets less attention compared to SGAT, and its future as drug target seems uncertain. 


\section{Inhibitors of Low-Affinity Sodium-Dependent Glucose Co-transporters (SGLT2)}

Compared to the previous categories discussed, this target represents a different potential approach for weight loss. The sodium-glucose co-transporter-2 (SGLT2) is a lowaffinity transport system that is specifically expressed in the kidney and plays an important role in renal glucose reabsorption in the proximal tubule. Competitive inhibition of SGLT2, leading to enhanced glucose and energy loss through the urine, was initially regarded a promising new therapeutic strategy for the treatment of hyperglycaemia in patients with type 1 or type 2 diabetes (see (46) for a recent review). However, some compounds are now also undergoing investigation for their potential effect on body weight. These include serglifozin (GSK-869682; clintrials.gov NCT00297180), canaglifozin (JNJ-28431754; clintrials.gov NCT00650806) and remogliflozin etabonate (GSK189075; clintrials.gov NCT00494767). Johnson and Johnson plan to file their canaglifozine before 2013 (47).

\section{Intestinal Microbiota as Future Target for Weight Management?}

A potential future strategy for weight loss that is currently receiving increasing attention is selective modulation of the intestinal micro flora. Some years ago, Gordon and coworkers $(48,49)$ discovered that intestinal bacteria appear to have an important effect on body weight. In addition, certain antibiotics can increase body weight in rats and mice, and human data indicate that the combination of vancomycin plus gentamycin is accompanied by a significant weight gain (50). Several mechanisms have been suggested, including the phenomenon of "energy harvesting" by the micro flora, production of specific short-chain fatty acids interacting with certain receptors including GPR41 and GPR43 (51), and changes in the pro-/antiinflammatory balance in the gut.

\section{TARGETS FOR REDUCING APPETITE OR INDUCING SATIETY OR SATIATION}

Pharmacological modulation of human eating behavior has proven to be extremely complex. People do not only eat to satisfy their hunger or appetite, but also for many other reasons, including sensory stimulation, sensory hedonics, in response to stress, for social interaction, against boredom, etc. (29-31,52,53). Several pathways are involved in regulating eating behavior with many redundant and compensation mechanisms in place. Before and during eating, sensory effects are generated through the taste, smell, temperature and texture of food. Cognitive effects play a role in the beliefs about the properties of the foods being eaten and their effects. Post-ingestive factors include the effects of gastric distension, rate of gastric emptying, release of intestinal hormones into the circulation and neural signaling via the Nervus vagus (see (54) for review). Signals and hormones originating from the GI tract are commonly called satiety signals and satiety hormones, respectively. They include the pancreatic hormone glucagon, cholecystokinin (CCK), GLP-1, PYY, etc. It should be noted that the term satiety hormones may be somewhat confusing, since most of them promote a process called satiation, which serves as trigger of meal termination. Meal termination is also stimulated by circulating levels of glucose, amino acids and lipids, which are directly sensed by the brain or through peripheral receptors (55). By contrast, the term satiety is typically used to describe processes that inhibit further eating during postprandial periods, determining meal frequency. Blood glucose concentration activates gluco-receptors in the hypothalamus, either acting to up-regulate hunger when blood glucose levels fall or up-regulate satiety when glucose concentrations rise. In the longer term, deposition of fat may lead to control of appetite by neuronal and hormonal signals via leptin. Within the central nervous system, systems involved in eating behavior share many mediators and pathways involved in, for example, the regulation of metabolism and mood state. This partly explains why several compounds with a relatively broad spectrum of activities have shown unacceptable side effects in the past. Vice versa, there are also several CNS drugs developed for other indications that show effects on eating behavior.

For the purpose of this review, two main approaches will be distinguished here:

- Modulation of nutrient sensing within the GI tract or through interference with signals transmitted to the brain or peripheral organs.

- Modulation of signal processing within the CNS, for example by interfering with neurotransmitter concentrations or activity.

\section{NUTRIENT SENSING WITHIN THE GI TRACT AND SIGNALLING TO THE BRAIN}

\section{Generation of Satiety Signals in the GI Tract}

According to most of the present views, endocrine biochemical signals are not regarded as major drivers for meal onset. So far, the only exception seems to be ghrelin, which is an orexigenic (stimulating eating) peptide hormone, surging just before meals and suppressed by ingested nutrients $(54,56)$. By contrast, satiation is a process that is 
delicately regulated by various signals originating from the stomach and gut. Along the GI tract, several receptor types are present that respond to nutrients and their immediate breakdown products, such as amino acids, small peptides, fatty acids or carbohydrates (51). Increasing evidence suggests that metabolites formed by bacteria or host cells within the GI tract are also involved in this sensing process (51). Receptors are located on so-called entero-endocrine cells (EECs) and on afferent nerve terminals (see also Fig. 1). By their shape and location, these entero-endocrine cells are well equipped to sense chemical structures in the lumen and to pass their information to small blood vessel and nerve terminals. Their apical side is in contact with the luminal contents, and their basolateral side is in contact with the vasculature of the lamina propria, neural cells, and with distant enterocytes. Remarkably, several entero-endocrine cell types throughout the gut also express taste receptors, including T1R2/3 sweet taste receptors, T2R-family bitter receptors, and the taste-specific $\mathrm{G}$ protein $\mathrm{G} \alpha$-gustducin $(57,58)$. An important finding has been that taste-like nutrient sensing is necessary for normal GLP-1 secretion. Expression of sweet taste receptors was also found to be decreased in diabetic subjects with elevated blood glucose concentration (58). In addition, endocannabinoids induce sweet taste (59). This suggests that intestinal "taste" signaling is under dynamic metabolic and luminal control. Nutrient signaling to the brain is a combination of endocrine and neural processes. Vagal afferent nerve fibers are forming the enteric nervous system, which communicates to the brain via the $\mathcal{N}$. Vagus. Nerve terminals in the mucosa contain specific receptors that recognize satiation peptides and nutrient-derived mediators (60).

Upon stimulation, several satiation-inducing peptides are being released by entero-endocrine cells, including cholecystokinin (CCK), bombesin, glucagon, glucagon-like peptide-1 (GLP-1), GLP-2, apolipoprotein A-IV, amylin, somatostatin, enterostatin, and peptide YY (PYY). Increasing evidence suggests that the development of satiation cannot be simply attributed to stimulation of specific receptors at defined locations. Instead, digestion, passage through the GI tract and satiation are acting in a cascade of events. Sensing and feedback occur via signals from multiple sites in the GI system, including the stomach, proximal small intestine, distal small intestine, colon, and pancreas $(52,54)$.

Satiation signals also interact with adiposity signals, in which leptin plays an important role. The central integration and control occurs by the hypothalamus, which is continuously informed about the nutritional, energetic and environmental status of the body. This complexity in signaling and cross-talk has often limited the clinical result of a single target drug, i.e. a molecule specifically acting on one receptor.

\section{Intestinal, Pancreatic and Peripheral Receptors and Local Feed-Back Mechanisms as Potential Targets for Satiation}

Considering the abundance and diversity of nutrientsensing receptors, it is understandable that they are receiving considerable interest as potential targets for satiety induction. This is also obvious from the high activity in the patent literature. Many GI receptors still have an orphan receptor status, but considerable progress is being made with their de-orphanization and characterization. The gut contains several types of receptors, for example Gprotein gustducin and G-protein-coupled receptors (including GPR119, 93, 55,120 and 40), TRPV type 1, and various other types including melanocortin, opioid and PPAR (51,58,61-66). So far, intensive research for pharmacological ligands that possess significant effects on body weight has not led to important breakthroughs. An interesting exception to this seems to be the G-proteincoupled receptor GPR 119. Initially, GPR119 was considered a potential new endocannabinoid receptor because of structural similarity and overlapping ligand selectively.

Two of the major endogenous ligands discovered so far are the fatty acid amides oleylethanolamide (OEA, Fig. 4) and N-oleoyldopamine (Fig. 4), which were originally also classified as endocannabinoids. The process of deorphanization of GPR119 and the demonstration that small molecule agonists are able to reduce body weight gain in rodents was first published in 2006 by Overton et al. (67) from OSI Pharmaceuticals (now Astellas). The receptor was shown to be Gos-protein coupled and predominantly expressed in pancreatic islets and gastrointestinal tract in humans and rodents. GPR119 agonists were found to increase intracellular cAMP, which in turn leads to increased GLP-1 secretion from entero-endocrine cells (67-69). Very recently, it was shown that there is also cross-talk between the satiety hormone PYY and the GPR119 receptor (60). Together, these discoveries have generated considerable interest in the search for smallmolecule GPR119 agonists as potential inducers of satiation, which is also illustrated by the robust activity in the patent area (70). Following the synthesis of the first ligands, including PSN632408 and AR-231,453 (Fig. 4), several pharmaceutical companies became active in developing GPR119 agonists and report activity from time to time. More examples and structures are available through the literature (70-72). Many of these compounds have shown interesting activities in animal models of type 2 diabetes and obesity, including a reduction of blood glucose without causing hypoglycaemia, a reduction of food intake and body weight, and reduced diabetes progression (69). The first compound that was advanced to the clinic, APD-668, was co-developed by Arena Pharmaceuticals (http://www. 
Fig. 4 Some GPRII9 ligands; the endogenous fatty acid amides oleylethanolamide (OEA) and Noleoyldopamine (ODA), and two synthetic compounds :

PSN632408 and AR-23|453.

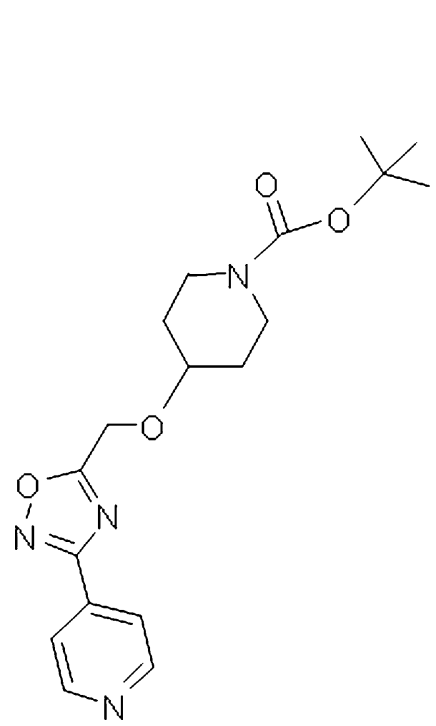

PSN632408<smiles>CCCCC/C=C\CCCCCCCC(=O)NCCc1ccc(O)c(O)c1</smiles>

$\mathrm{N}$-oleoyldopamine (ODA)

$\mathrm{HO}$

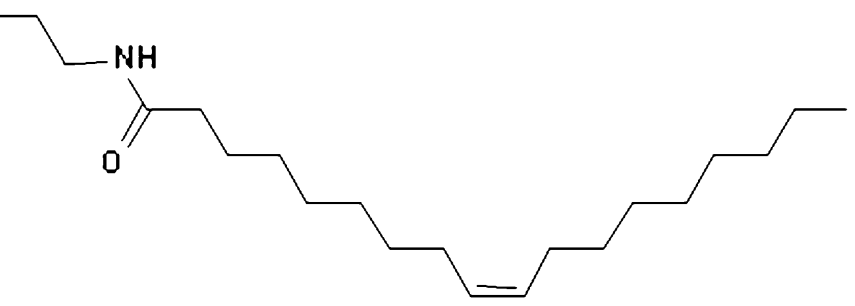

Oleoylethanolamide (OEA)<smiles>COc1ccc(Nc2ncnc(N3CCC(c4nc(C(C)C)no4)CC3)c2[N+](=O)[O-])c(F)c1</smiles>

AR231453 arenapharm.com) and Ortho McNeil. It showed improvement of glucose control in diabetic patients. Nevertheless, the partners chose to give priority to the related compound APD-597 (structure not disclosed), which is now in phase I. Apparently, diabetes is the primary indication at this moment (73). Metabolex (www.metabolex.com) initiated a phase I trial with MBX-2982 (structure not disclosed) in March 2008; in November 2008, phase Ia data were presented. The drug was rapidly absorbed and showed a half-life allowing oncedaily dosing. MBX-2982 also caused dose-dependent reductions in glucose and increased GLP-1 following a mixed meal.
The compound is now further developed together for diabetes with Sanofi-Aventis (74). OSI pharmaceuticals is currently in phase II with PSN-821. Taken together, study results with GPR119 agonists are encouraging.

\section{The Endocannabinoid System: Not a Lost Target}

The endocannabinoid system modulates food intake and energy metabolism at different levels, starting from receptors within the GI tract to the regulation of hedonic rewarding in the brain $(33,75)$. It is regarded as a distinctive 
pleiotropic regulator of energy uptake and storage and of nonhomeostatic eating behavior $(76,77)$. In the past, these mechanisms were beneficial in order to survive periods of food shortage. The first generation CB1 blockers, including rimonabant, were reverse agonists developed to act on receptors present within the CNS. Later, it became clear that CB1 receptors were also present outside the CNS. Furthermore, it is now assumed that the central effects of rimonabant are responsible for the short-term reduction of food-intake, whereas the more sustained effects on body weight and the improvement of insulin resistance and blood lipids are more due to its peripheral actions. The failure of rimonabant because of depression-related side effects in predisposed persons shocked the pharma industry. By the end of 2008, at least nine companies terminated active development projects with CB1 blockers, including some with compounds in a welladvanced stage of development such as taranabant (Merck) and CP-945,598 (otanabant, Pfizer). However, interest in CB1 modulation in relation to metabolic diseases has not completely disappeared $(76,78)$, and, in principle, a number of therapeutic options have remained. These include the use of CB1 neutral antagonists or partial agonists as opposed to reverse agonists, such as rimonabant, or by using so-called peripherally restricted $\mathrm{CB} 1$ antagonists (78-83). Several peripherally restricted $\mathrm{CB} 1$ blockers have been synthesized and characterized $(82,84,85)$. These second-generation CB1 blockers are more lipophilic, leading to lower brain concentrations. Some compounds have shown sustained effect on weight without giving the temporal suppression of food intake seen with rimonabant $(82,84,85)$. Fig. 5 shows some examples. LH-21 (84) was one of the first compounds described in this class, and the 7-carbamoylmethyl-pyrazolecarboximide derivatives have been synthesized by Danish 7TM Pharma (85). In early 2010, 7TM Pharma announced that it had successfully completed a phase I clinical trial with the drug candidate TM38837 showing favorable pharmacokinetic properties in humans (86).

\section{Compounds Interfering with Signaling Pathways to the Brain}

As earlier described, satiety signals from the gut are transferred to the brain via neural pathways and through the circulation via peptide hormones. The latter offers options for pharmacological intervention, which in some cases has provided effective approaches. Some examples are listed in Table II.

\section{Amylin Analogues}

Amylin is a peptide of 37 amino acids which is co-released with insulin by the pancreas $(56,87)$. Its primary sites of action are thought to be located in the brainstem. Amylin

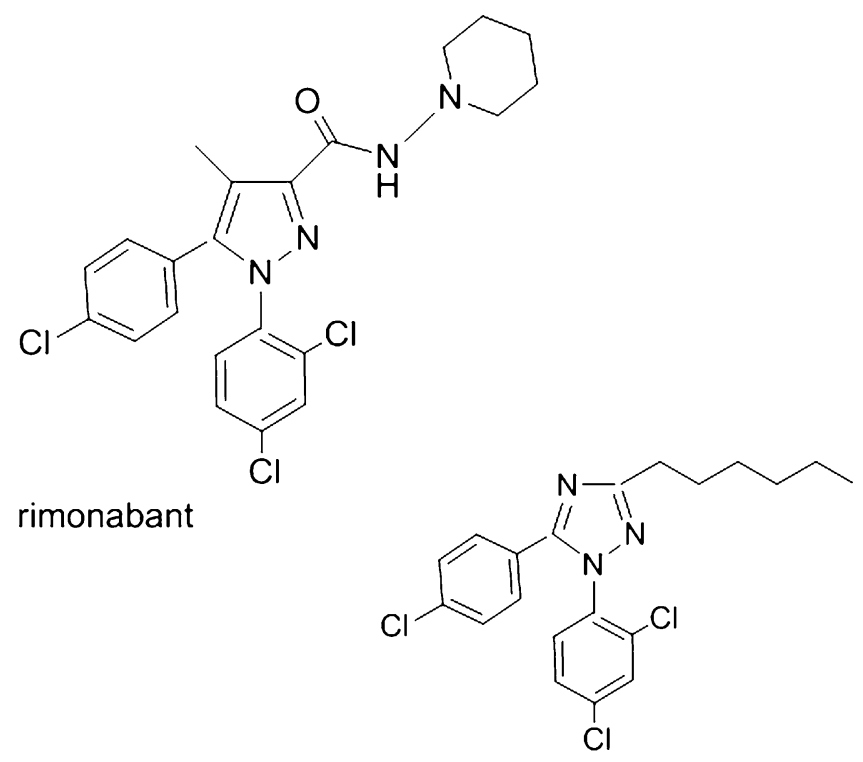

LH-21
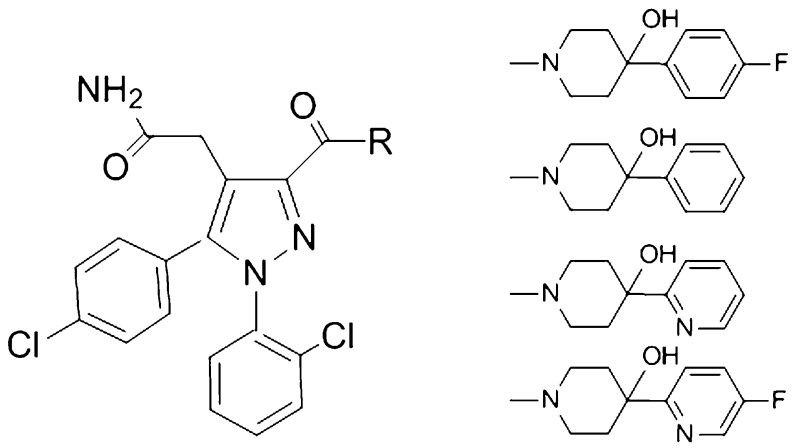

$\mathrm{COOH}$

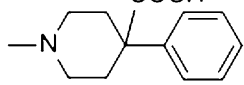

\section{7-carbamoylmethyl-pyrazole-3-carboximides}

Fig. 5 Chemical structure of rimonabant, the first clinically developed CB I blocker, which failed during (US) and after (EU) registration and some examples of second-generation CBI blockers. While $\mathrm{LH}-2 \mathrm{I}$ has not been developed into the clinic, compounds belonging to the 7-carbamoylmethylpyrazole-carboximide derivatives are still in development.

analogues were originally developed for therapeutic use in diabetes but were also shown to cause weight loss, for example in obese patients with type 2 diabetes (88). The use of the endogenous peptide might increase the risk for the formation of amyloid fibrils (56). However, the analogue pramlintide $\left(\right.$ Symlin $^{\circledR}$, Pubchem CID 16132446), developed by Amylin Pharmaceuticals, does not contain the sequence that is considered responsible for this effect. Pramlintide is already available in the US as an injectable antihyperglycemic drug for diabetic patients who also use insulin. An interesting preparation which is currently in development is the combination of pramlintide with metreleptin (89). Metreleptin is a synthetic analogue of 
Table II Some Examples of Pharmacological Interventions Via Gut Hormone Signaling

\begin{tabular}{lll}
\hline Gut hormone & Approach & Example(s) \\
\hline Amylin & Peptide analogues & Pramlintide \\
PYY & PYY(3-36) analogues & Nasal formulations, development discontinued for the time being \\
Pancreatic polypeptide & PP analogues/Y4 agonists & TM-30339, obinepitide (dual-analogue of PYY3-36 and PP) \\
GLP-I & Stable analogues & Exenatide, liraglutide \\
Oxyntomodulin & Analogues & ? TKSI 225 \\
Ghrelin & Vaccination/mRNA aptamers & NOX-BII Spiegelmers \\
Leptin & Analogues (in combinations) & Metreleptin-pramlintide combination \\
\hline
\end{tabular}

leptin. Normally, sensitivity to leptin is reduced in obesity, which limits its therapeutic potential. However, pramlintide was found to inhibit this process. In a 20-week trial, the combination induced a weight loss of $12.7 \pm 0.9 \%(11.5 \pm$ $0.9 \mathrm{~kg}$ ) in obese persons (89). Another second-generation amylin analogue in development was davalintide (30). However, recently, Amylin Pharmaceuticals and Takeda (Japan) announced they were giving priority to the pramlintide/metreleptin combination and discontinuing development of davalintide. Phase II studies demonstrated that the weight-loss efficacy and tolerability profile of davalintide was not better than that of pramlintide and was inferior to that of the pramlintide/metreleptin combination (90).

\section{PYY Analogues}

PYY (1-36) is a 36-amino-acid polypeptide synthesized by entero-endocrine cells of the L-type, mainly in the distal gut. The main circulating form of the hormone is $\mathrm{PYY}(3-$ 36), which is formed after partial cleavage of PYY(1-36) by dipeptidyl peptidase IV (56). PYY is considered to be a principal mediator of the 'ileal brake' reflex, which is a feedback mechanism that slows gastric emptying and intestinal transit in response to nutrients (fat, protein, and carbohydrates) arriving in the distal small intestine. The effects of PYY3-36 are mediated via the Y2-receptor, which is found throughout the central nervous system, in the nodose ganglion, and on Vagal afferents. It has also been suggested that weight loss induced by PYY3-36 occurs in part by modulating energy expenditure and fuel partitioning (56). Following the discovery of Batterham et al. (91) that peripheral administration of PYY3-36 can cause a reduction of food intake in rodents and in obese and normal-weight humans, other studies confirmed the anorectic action of PYY3-36. However, in their review, Boggiano et al. (92) take a very skeptical position on the potential of PYY3-36-based therapies in practice. A phase II trial in 2008 with a PYY336 nasal spray showed encouraging results (56). Nevertheless, the development of that formulation was stopped, as the results did not meet the primary endpoints. At present, there appears to be little activity with PYY-based approaches (30).

\section{Pancreatic Polypeptide Analogues}

Pancreatic polypeptide (PP) is a 36-amino-acid peptide categorized in the same family as PYY. However, in contrast to PYY, it is mainly secreted by the pancreas and, to a lesser extent, by the colon (56). Plasma PP concentrations rise in a biphasic manner following nutrient ingestion. This increase is proportional to the caloric load of the meal with concentrations remaining elevated up to $6 \mathrm{~h}$ after a meal. This suggests that PP exerts its effects on feeding mainly by inducing satiety. PP has highest affinity for Y4-receptors in brainstem and hypothalamus, followed by Y1- and Y5receptors. Several studies demonstrate that $\mathrm{PP}$ can reduce food intake. Danish 7TM Pharma has developed TM30339, a synthetic analogue of PP and a selective Y4receptor agonist. The compound demonstrated weight loss in diet-induced obese mice. According to the company, the compound showed good safety and tolerability data and is now in phase II. However, indications have apparently shifted to gastrointestinal disorders, including mucositis, malabsorphtion, ulcerative colitis, Crohn's disease and short bowel syndrome (93). The same company has also developed the dual PP and PYY (3-36) analogue obinepitide (http:// www.uniprot.org/uniprot/P01298), with agonist activity both for the Y2 and Y4 receptor (94). According to 7TM Pharma, the compound had greater weight-loss-inducing effects in diet-induced obese mice than PYY3-36. The compound is now in phase I/II, and once-a-day subcutaneous administration in obese subjects inhibited food intake at a statistically significant level up to $9 \mathrm{~h}$ after dosing.

\section{GLP-I Analogues}

Among the gut hormones, GLP-1 is currently the most promising and advanced target for pharmacological weight management. Natural GLP-1 is synthesized by intestinal Lcells and subsequently cleaved to its active fragments GLP17-37 and GLP-17-36 amide, the latter being the major circulating form. GLP-1 is rapidly inactivated by dipeptidyl peptidase IV (DPP-IV), leading to an elimination half-life of only 1-2 min. The peptide acts on the GLP-1 receptor, 
which is widely expressed throughout the CNS and peripheral tissues (56). GLP-1 receptors in peripheral tissues, including the stomach, may also be important in meal termination and possibly satiety. Administration of GLP-1 causes a dose-dependent reduction of food intake in experimental animals and in both lean and obese humans. Two main strategies are being followed to combat the extremely short half-life of native GLP-1. The first is by producing more stable GLP-1 analogues; the second is by inhibiting DPP IV, which is catalyzing the GLP-1 breakdown. For weight management, stable GLP-1 has so far produced the best results. A first breakthrough was the discovery of the natural GLP-1 analogue exendin-4 in the venom of a lizard called Gila monster. Based on this molecule, Amylin Pharmaceuticals and Eli Lilly developed exenatide $\left(\right.$ Byetta $\left.^{\circledR}\right)$, which is already on the market as an adjunct to current diabetes therapies. The observation that the drug not only improved glycemic control, but also caused a reduction in body weight, stimulated further research in this direction. An unpleasant side effect of Exenatide is nausea, in particular during the initial phase of treatment. Furthermore, patients can develop antibodies to the drug, which sometimes leads to reduced efficacy. Exenatide needs to be administered twice daily by subcutaneous injection, which is also a disadvantage. To overcome this, a once-weekly injection preparation named exenatide LAR (Amylin/Lilly/Alkermes) is currently under development. Phase III trial results have demonstrated good blood sugar control and weight loss, especially in patients for whom metformin or sulphonylureas are not effective (95). As expected, exenatide LAR has a side-effect profile similar to Byetta ${ }^{\circledR}$. A promising alternative is liraglutide (Novo Nordisk), a GLP-1 analogue with 97\% similarity to human GLP-17-37 (96). Due to the addition of a side chain, liraglutide binds to albumin, leading to a half-life of about 13 hours. Liraglutide has already been approved for use in diabetes. Recently, the NN8022-1807 Study Group (96) reported the results of a double-blind, placebocontrolled 20-week trial, with open-label orlistat comparator in 19 sites across Europe. In total, 564 non-diabetic individuals with a BMI between 30 and $40 \mathrm{~kg} / \mathrm{m}^{2}$ participated. Mean weight loss with the different doses of liraglutide was between 4.8 and $7.2 \mathrm{~kg}$, compared to $2.8 \mathrm{~kg}$ with placebo and $4.1 \mathrm{~kg}$ with orlistat. More individuals $(76 \%, n=70)$ lost more than $5 \%$ weight with liraglutide $3.0 \mathrm{mg}$ than with placebo $(30 \%, n=29)$ or orlistat $(44 \%$, $n=42$ ). Liraglutide also showed beneficial effects on blood pressure and pre-diabetes symptoms. Although nausea and vomiting occurred at higher frequency in the liraglutide groups, these side effects were considered transient and rarely led to discontinuation of treatment. As liraglutide still needs to be administered by injection, Novo is developing a long-acting oral GLP-1 analog (NN9924) that utilizes sodium N-[8-(2-hydroxybenzoyl) amino] caprylate (SNAC) carrier technology (97). A phase I trial was started early 2010.

\section{Oxyntomodulin (OXM)}

OXM consists of 37 amino acids of which 29 are in common with GLP-1. Levels peak at $30 \mathrm{~min}$ and in proportion to caloric intake, remaining elevated for several hours (56). Although OXM has a 50-fold lower affinity for binding at the GLP-1 receptor, it has an equal potency for inhibiting food intake. Studies have shown that OXM reduces food intake and causes reduced weight gain in rodents. Acute OXM administration reduced food intake in lean volunteers, and chronic OXM subcutaneous injections in obese individuals induced an average weight loss of $2.3 \mathrm{~kg}$ after 4 weeks, compared to $0.5 \mathrm{~kg}$ in the control group (56). Despite this, only a small number of development projects appear to be in an advanced stage. Thiakis Limited (London, UK) started in March 2008 investigating the potential of their OXM analogue, TKS1225. Following the take-over of Thiakis by Wyeth in December 2008, which was in turn acquired by Pfizer in 2010, the present status of this molecule is unknown.

\section{Cholecystokinin-I (CCK) Agonists}

CCK is secreted by I-cells in the proximal part of the small intestine. The hormone is formed by post-translational cleavage of the pre-pro-CGK polypeptide, which undergoes further proteolysis to a cocktail of active peptides with varying numbers of amino acids (see (98) for review). Following nutrient ingestion, circulating CGK levels start to increase bi-phasically at $15 \mathrm{~min}$, reaching a peak at around $25 \mathrm{~min}$, and remain elevated for approximately $3 \mathrm{~h}$ (56). Presently, there are two G-protein-coupled CGK receptors known. CCK-1 receptors are mainly present in the gastrointestinal tract, myenteric plexus and Vagal afferents, while CCK-2 receptors are predominantly expressed in the brain. It is widely accepted that CCK-induced satiation is largely mediated by the CCK-1 receptors (56). Although administration of CCK has shown to cause a reduction of food intake, its value for anti-obesity therapy has proven to be limited so far. It appears that CCK is more important in satiation than satiety, which could lead to compensation through increasing meal frequency. GSK has stopped the development of their compound GI 181771 after phase II clinical trials failed to show any significant weight loss (99). A limitation of that study might have been that participants were allowed to eat ad libitum and might have compensated their energy intake by increasing meal frequency. At the end of 2008, Pfizer also discontinued development of a CCK agonist (CE-326597) after phase II. 


\section{Blocking Ghrelin Activity}

In contrast to the previously described gut hormones, ghrelin stimulates eating. Ghrelin is a 28-amino-acid polypeptide released from the gastric oxyntic cells. Its plasma levels show a marked rise shortly before the start of a meal (100). The peptide increases food intake both in rodents and humans. Ghrelin has been shown to act on the growth hormone secretagogue receptor 1A (GHS-Rla), which is expressed in several brain areas (101). In order to bind, ghrelin needs to be bio-activated through acylation with a medium-chain fatty acid. The enzyme involved, gastric O-acyltransferase (GOAT), has also attracted interest as a potential target to modulate ghrelin activity (102). Some discussion is remaining on the potential role of nonacylated ghrelin (56). Recent studies suggest that ghrelin activates reward-seeking circuits and increases the incentive value of palatable foods in particular (101). To modulate ghrelin effects, blocking the receptor using small-molecule antagonists seems an interesting option. Indeed, several GHS-R la blockers were synthesized and characterized (for example $(103,104))$. However, no molecules appear to have reached the clinical phase to date. Alternative strategies are targeting ghrelin itself by ghrelin RNA aptamers (so-called Spiegelmers, including NOX-B11) developed by Berlinbased company NOXXON Pharma AG (105) or by an anti-ghrelin vaccine (106). The aptamer strategy was licensed to Pfizer and has not yet reached clinical testing. Although ghrelin vaccination has shown promising results in animals (106), human tests have not given suitable results so far.

\section{Leptin Analogues}

Leptin is not a gut hormone but secreted by adipose tissue. It has been shown to act as both a short- and long-term regulator of energy balance and to signal in the arcuate nucleus, where it inhibits NPY/AgRP signaling and stimulates POMC/CART signaling. After the discovery of leptin, expectations were high regarding its potential to reduce appetite. However, early clinical trials of leptin therapy for the treatment of obesity failed because the majority of obese patients exhibit leptin resistance. Recently, though, leptin has reemerged as a targeted antiobesity therapeutic in combination with the amylin analogue pramlintide (see section on amylin analogues).

\section{DRUGS ACTING ON NEUROTRANSMISSION AND RECEPTORS IN THE CNS}

The regulation of food intake and body weight within the central nervous system occurs at different levels with multiple systems being involved. A detailed description falls beyond the scope of this article. For recent reviews, see for example (32,55,107-109). Briefly, different stimuli, including satiety hormones, signal coming in via the $\mathcal{N}$. vagus, and nutrients in plasma are sensed and integrated by the brainstem and the hypothalamus. In the arcuate nucleus of the basal hypothalamus, the orexigenic (appetite stimulating) neuropeptide Y (NPY) and agouti-related protein (AgRP)-expressing neurons counterbalance anorexigenic pro-opiomelanocortin (POMC) and cocaine-amphetamineregulated transcript (CART)-expressing neurons (see also Fig. 1). Signaling at neuronal Y1 and Y5 receptors produces the orexigenic effects of NPY, whereas Y2- and Y4-receptor signaling produces an anorexic phenotype due to their presynaptic inhibition of NPY release. The latter two receptors are also the targets of the gut hormones PYY and PP that have been discussed in the previous section. The resulting level of metabolic balance in the basal hypothalamus is integrated with signals from brainstem centers and input from the lateral hypothalamus and further projected to so-called second-order hypothalamic neurons. The liking (pleasure/palatability) and wanting (appetite/incentive motivation) associated with the increased availability and variety of food are processed in the cortico-limbic structures, a series of synaptically interconnected circuits linking the prefrontal cortex, amygdala, ventral tegmental area (VTA), nucleus accumbens (NAc) and ventral pallidum with the medial forebrain bundle (MFB). Despite this complexity and apparently tightly regulated balance, there is a remarkably high research activity in the development of compounds for weight management that act within the CNS. Some of the most advanced preparations in development belong to this category. However, the contribution of old molecules, initially developed for other indications, is also considerable in this group. Remarkable is also the emergence of combination therapies in this category, aiming to modulate different targets in parallel, while reducing the dose of the individual compounds to minimize side effects. Table III briefly summarizes the main representatives and targets of this category. Note that many CNS compounds are modulating different targets or pathways in parallel.

\section{Compounds Predominantly Modulating Local Availability of Dopamine, Norepinephrine and Serotonin in the Brains}

This group also comprises the amphetamine-related compounds fenfluramine (Fig. 6) and dexfenfluramine, which were banned in 1997. Another amphetamine derivative, phentermine (Fig. 6), once popular in fen-phen combinations with fenfluramine and dexfenfluramine, is currently approved in the US as a short-term treatment for 
Table III Some Examples of Pharmacological Targets Within the CNS

\begin{tabular}{lll}
\hline Assumed (predominant-) target & Mechanism of action & Example(s)of compounds (late-stage development or approved) \\
\hline Dopamine/norepinephrine/serotonin ${ }^{a}$ & Inhibition of uptake & Subitramine \\
& & Bupropion \\
& & Tesofensine \\
& Stimulation of release & Phentermine \\
GABA & Stimulation of GABA activity ${ }^{b}$ & Topiramate (in combinations) ${ }^{b}$ \\
& & Zonisamide (in combinations) \\
Serotonin-receptor $\left(5-\mathrm{HT}_{2 c}\right)$ & Agonist & Lorcaserin $^{b}$ \\
Serotonin-receptor $\left(5-\mathrm{HT}_{6}\right)$ & Agonist & Several compounds in early clinical phase \\
MC4-receptor & Agonist & Preclinical/early clinical \\
MCH-receptor type I & Antagonist & NGD-47I5 \\
Histamine (H3-) receptor & Antagonist & Preclinical and early clinical phase \\
NPY (Y5) receptor & Antagonist & Velneperit \\
AgRP & Inhibition & TTP435 \\
PTPIB & Inhibition & Trodusquemine \\
\hline
\end{tabular}

${ }^{a}$ often affecting different neurotransmitters with different relative potency

${ }^{b}$ combined with other mechanisms, partly unresolved

weight loss. Phentermine is thought to stimulate the release of norepinephrine and dopamine (30). As will be discussed later, the compound is now under investigation as part of a combination preparation $\left(\right.$ Onexa $\left.^{R}\right)$ together with topiramate. Subitramine (Fig. 6) is one of the two currently approved

Fig. 6 Chemical structures of some compounds predominantly acting by increasing local concentrations of dopamine, norepinephrine and $5-\mathrm{HT}$ in the brain: fenfluramine (banned in 1997), phentermine, and sibutramine (recently withdrawn in Europe).<smiles>CCNC(C)Cc1cccc(C(F)(F)F)c1</smiles>

\section{fenfluramine}<smiles>CC(C)CC(N(C)C)C1(c2ccc(Cl)cc2)CCC1</smiles>

sibutramine weight-loss drugs in the US. Since early 2010, it is no longer on the market in Europe. The compound acts centrally as an uptake inhibitor of norepinephrine, serotonin and dopamine. The demethylated metabolites are more active than the parent compound. Subitramine is considered an effective weight-loss drug, showing body-weight reductions between 5 and $10 \%$ in most trials (30). Side effects include constipation and increased blood pressure and heart rate.

Bupropion (Fig. 7) is a dopamine and norepinephrine reuptake inhibitor and has also antagonist activity for<smiles>CC(NC(C)(C)C)C(=O)c1cccc(Cl)c1</smiles>

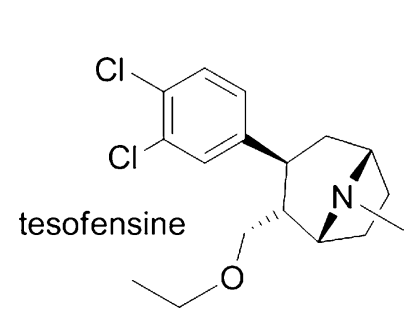

Fig. 7 Chemical structures of bupropion (a dopamine and norepinephrine reuptake inhibitor with antagonist activity for nicotine receptors) and tesofensine (a dopamine, norepinephrine and serotonin reuptake inhibitor in development). 
nicotine receptors $(30,110,111)$. It was originally developed as an antidepressant and for smoking cessation, for which it is approved in the US, but later showed utility in the treatment of obesity (110,111). Studies have shown that the compound can cause effective, long-term (1-year) weight loss when combined with lifestyle modification, and it appears to be more effective in patients not suffering from depression (111). It is also suggested that bupropion could serve as a valuable adjunct therapy to elevate mood in depressed patients in whom weight gain, secondary to antidepressant therapy, is an issue (111). Bupropion is currently also under clinical investigation in two different combinations, one together with the anti-epileptic drug zonisamide $\left(\right.$ Empatic $\left.^{\circledR}\right)$ and the other with the opioid antagonist naltrexone (Contrave ${ }^{\circledR}$ ). These will be discussed in a next section.

Tesofensine (Fig. 7) is a dopamine, norepinephrine and serotonin reuptake inhibitor developed by the Danish company Neurosearch. The compound has successfully passed phase II clinical testing (ClinicalTrial.gov NCT00394667), in which it showed dose-dependent weight loss (112), and has just entered phase III testing (30).

\section{Combination Therapies Based on Existing Drugs}

Interestingly, two older compounds of the previously described class of compound modulating levels of monoamines, phentermine and bupropion, are currently undergoing their renaissance in combination preparations with other existing drugs. Two of these combinations, Contrave ${ }^{\circledR}$ (bupropion plus naltrexone) and Qnexa ${ }^{\circledR}$ (phentermine plus topiramate) have already passed phase III testing. With the third combination, Empatic ${ }^{\circledR}$ (bupropion plus zonisamide), phase III testing will probably start shortly. The matching compounds in these combinations were initially developed as anti-epileptic drugs (zonisamide and topiramate) or as opioid antagonist (naltrexone). Topiramate and zonisamine are known to interact with different pathways, including GABA-ergic transmission. However, whilst GABA plays an important role in the brain, GABArelated targets do not appear to have provided practical strategies for weight management so far. The same holds true for opioids. Although there is considerable evidence that $\mu$-, $\kappa$ - and $\delta$-opioid receptors located in the rewardrelated brain areas are involved in control of food intake, this has not resulted in new molecules for weight management (30). One of the explanations might be that opioid antagonists as monotherapy have a rather complex effect on eating behavior, mainly affecting hedonic components and not satiety or satiation (30). Furthermore, the opioid system has many connections and functions within the CNS, which also increase the risk for side effects when single compounds would be used at pharmacologically active doses.

\section{Phentermine Plus Topiramate (Qnexa®)}

The amphetamine derivative phentermine (Fig. 6) is currently approved in the US as a short-term treatment for weight loss (recommended dose $37.5 \mathrm{mg} /$ day), whereas topiramate (Fig. 8) is indicated for treatment of seizures (recommended dose $400 \mathrm{mg} /$ day) or prevention of migraine headaches (recommended dose $100 \mathrm{mg} /$ day). The use of topiramate for weight management is a typical example of serendipity in the discovery of drugs in this area. It was not only discovered incidentally as anti-convulsant, but was also shown to possess anti-craving and weight loss effects (108). The mechanism(s) by which topiramate induces weight loss effects are still largely unknown. The combination, given in a slow-release formulation intended for once-daily administration allows lower doses of the individual compounds and is reported to cause fewer side effects than the individual compounds. Results from the recent EQUIP phase III trial sponsored by Vivus Inc. (Clintrial.gov NCT00554216), in which 1267 persons with a mean BMI of $42 \mathrm{~kg} / \mathrm{m}^{2}$ were enrolled for 56 weeks, indicate that the combination of $15 \mathrm{mg}$ phentermine with $92 \mathrm{mg}$ topiramate resulted in a mean weight loss of $14.4 \%$, whereas persons in the placebo group lost 2.2\% (113). Results were also in agreement with the FDA efficacy benchmarks in terms of $\%$ of persons showing more than 5, 10 or $15 \%$ weight loss. This was associated with significantly different (from placebo) reduction in waist circumference and systolic and diastolic blood pressure. In another phase III study (QONQUER), the combination

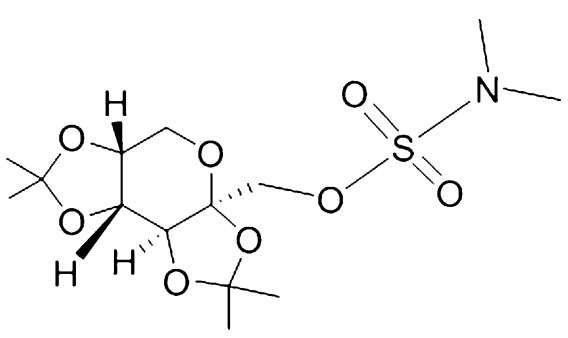

topiramate

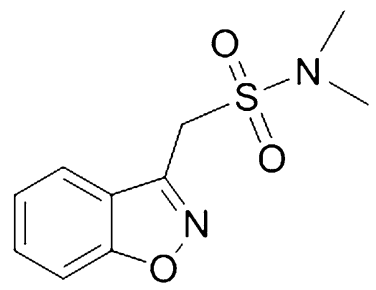

\section{zonisamide}

Fig. 8 Structures of topiramate and zonisamide, originally developed as anti-epileptic compounds. Currently under development in combination preparations. 
showed beneficial effects on triglyceride levels and HbAlc. No major side effects have been reported or safety issues raised so far. However, taken the known side effects of both drugs at higher doses (30), it is predictable that authorities will be watchful in the further processes. Indeed, FDA has recently (October 2010) declined to approve Qnexa based on the current data, asking for more study results and more information on possible risks.

\section{Bupropion plus Zonisamide (Empatic $\left.{ }^{\circledR}\right)$}

Bupropion (Fig. 7) has been discussed in the previous section. The combination with the anti-epileptic compound zonisamide (Fig. 8) has been reported to have higher efficacy with fewer side effects. Like topiramate, zonisamide is an anti-convulsant compound that has been shown to induce weight loss (114). It is supposed to act via mechanisms that are partly different from those of topiramate, affecting GABA, serotonin, and dopamine-regulated processes (30). In a phase IIb trial lasting 24 weeks, involving 729 obese subjects, mean weight loss with Empatic-360 (bupropion $360 \mathrm{mg} /$ zonisamide $360 \mathrm{mg}$ ) was $9.9 \%$ and $7.7 \%$ with Empatic-120 (bupropion $360 \mathrm{mg} /$ zonisamide $120 \mathrm{mg}$ ), respectively. The placebo group lost $1.7 \%$ of their body weight (111). In addition, significantly more subjects in the groups receiving the combinations lost $\geq 5 \%$ of their baseline weight as compared with subjects in the placebo group. Adverse events were similar to those reported for each of the individual drugs. This combination is anticipated to move to phase III testing soon.

\section{Bupropion Plus Naltrexone (ContraveR)}

This third combination of existing drugs combines bupropion with the opioid antagonist naltrexone and is developed by the same company (Orexigen Therapeutics, Inc.) as Empatic $^{\circledR}$. Like bupropion, naltrexone is also already on the market. Synergistic effects were found in preclinical testing and during phase II studies. It has been suggested that the $\mu$ - and $\kappa$-antagonist naltrexone inhibits a negative feedback loop that limits the $\alpha$-MSH response of POMC neurons following stimulation by bupropion. The resulting $\alpha$-MSH then acts as an anorexigenic signal via stimulation of the MCR4 receptor (see also next section). The company has submitted an NDA to the FDA following a series of successful phase III trials that were finished in 2009. In these trials, the combination met the FDA efficacy benchmark causing at least $5 \%$ loss of body weight in approximately $50 \%$ of patients treated with Contrave-32 (bupropion $360 \mathrm{mg}$ SR+naltrexone $32 \mathrm{mg} \mathrm{SR}$ ) as compared to $16-18 \%$ of placebo patients. This was accompanied with improvements of cardiometabolic risk factors. The company also announced that the combination shows

beneficial properties in obese persons with diabetes and obese persons with major depression (115).

\section{Serotonin (5-HT) Receptor Ligands}

The inverse relation between an increased availability of serotonin in certain brain areas and food intake has already been recognized for a long time, for example from the effects of fenfluramine and selective serotonin reuptake inhibitors like fluoxetine. However, due to side effects, non-selective modulation of brain serotonin levels were generally not regarded as an attractive target for weight management. During further investigations to untie the different serotonin actions to achieve better selectivity, a number of 5-HT receptors were identified as potential candidates (see (116) for review). Of those, the $5-\mathrm{HT}_{2 \mathrm{C}}$ and $5-\mathrm{HT}_{6}$ receptors have so far delivered the most promising candidates.

\section{5-HT2C Agonists}

The role of the brain $5-\mathrm{HT}_{2 \mathrm{c}}$ receptors in reducing food intake was discovered by the end of the last century while investigating the mechanisms of action of fenfluramine in rodents $(117,118)$. As a result, several companies started to develop selective $5-\mathrm{HT}_{2 \mathrm{C}}$ agonists as possible candidates for obesity (116,119). Although a number of compounds have reached phase II testing, selectivity for $5-\mathrm{HT}_{2 \mathrm{c}}$ over (peripheral) 5- $\mathrm{HT}_{2 \mathrm{~B}}$ receptors and the development of tolerance may limit their success (116). However, a promising molecule is lorcaserin (APD356, Fig. 9), a structural analogue of dexfenfluramine.

The compound is a selective $5-\mathrm{HT}_{2 \mathrm{C}}$ agonist with $\sim 15$ fold and 100-fold selectivity over that for 5-HT $2 \mathrm{~A}$ and 5$\mathrm{HT}_{2 \mathrm{~B}}$ receptors, respectively (120). Its efficacy has been demonstrated in a number of studies. For example, during a two-week phase II trial with 469 obese persons (BMI 30$45 \mathrm{~kg} / \mathrm{m}^{2}$ ), lorcaserin caused dose-dependent weight loss up to $3.3 \mathrm{~kg}$ (placebo adjusted) in the group receiving lorcaserin $10 \mathrm{mg}$ two times daily. The percentages of patients completing the trial who lost $\geq 5 \%$ of their initial body weight were $2.3,12.8,19.5$, and $31.2 \%$ with placebo, $10 \mathrm{mg}$ per day, $15 \mathrm{mg}$ per day and $10 \mathrm{mg}$ two times daily, respectively (120). After completing a phase III clinical trial program, the company Arena Pharmaceuticals has submitted a New Drug Application to the FDA in December 2009, based on data from 18 clinical trials with, in total 8,576 patients, which were evaluated for periods up to two

Fig. 9 Lorcaserin, a selective 5- $\mathrm{HT}_{2 \mathrm{C}}$ agonist currently in the registration phase.

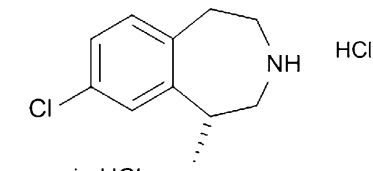

Iorcaserin $\mathrm{HCl}$ 
years (121). However, in September-October 2010, the FDA rejected the application because of safety issues that had been found in the preclinical data files. The applicants expressed their confidence in being able to alleviate these concerns, but at this stage it is unclear what the consequences for the further development of lorcaserin are.

\section{5-HT6 Agonists}

Another serotonin-associated target that is increasingly receiving attention is the $5-\mathrm{HT}_{6}$ receptor (see $(116,119)$ for reviews). The $5-\mathrm{HT}_{6}$ receptor is almost exclusively distributed within the central nervous system, which is rather unusual for a member of the serotonin receptor family. This is considered an advantage, as this facilitates selective modulation. The $5-\mathrm{HT}_{6}$ receptor has also become an attractive target for potential new antipsychotics and antidepressants. Many new 5-HT6 ligands have been synthesized with different structures (119). Among these, a number of compounds have shown effects on food intake or body weight in rodents, and some have entered clinical testing. The next few years will be decisive in demonstrating the potential of this target.

\section{Dopaminergic Ligands}

Compared to 5-HT receptors and despite the role of dopamine in regulating eating behavior, dopamine receptors do not appear to be considered as attractive targets at the moment. Preclinical studies suggest that D3 antagonists can be effective in reducing food intake (122). GlaxoSmithKline is currently investigating the D3 antagonist GSK598809 for use with compulsive overeating (ClinicalTrials.gov NCT01039454).

\section{MC4R (Melanocortin 4 Receptor) Agonists and MCH-RI (Melanin-Concentrating Hormone Receptor I) Antagonists}

The melanocortin system plays an important role in the central regulation of energy balance (123). The POMC (pro-opiomelanocortin) gene encodes several anorexigenic peptides that can activate at least five melanocortin receptor subtypes. These peptides include $\alpha-, \beta-, \gamma$-melanocyte-stimulating hormone $(\alpha-\mathrm{MSH}, \beta-\mathrm{MSH}$ and $\gamma$-MSH$)$ and adrenocorticotropin (ACTH). Of the different receptors, the melanocortin 4 receptor (MC4R) is receiving considerable interest as a potential target. Several smallmolecule agonists have been synthesized. See for structures for example (124) and for a very extensive list also (125). The clinical usefulness of this group remains to be established. Results with the MC4R agonist MK-0493 from MSD in humans were disappointing (126).
Melanin-concentrating hormone $(\mathrm{MCH})$ is an endogenous small cyclic peptide that increases food intake via interaction with the MCH-R1 receptor. MCH-R1 antagonists have been shown to inhibit food-intake in rodents, and several of such compounds have been synthesized $(125,127)$. Remarkably, cardiovascular side effects involving hERG binding and the potential for subsequent druginduced QT prolongation have presented major hurdles in a significant number of MCH-R1 research programs (127). Nevertheless, some molecules, including NGD-4715 (Fig. 10), have reached phase II. Another example is BMS830216 (Bristol-Myers Squibb), which is also entering phase II (ClinicalTrials.gov NCT00909766).

\section{H3 Receptor Antagonists}

Central histamine signaling has been implicated in appetite regulation, and inhibition of $\mathrm{Hl}$ receptor signaling or stimulation of $\mathrm{H} 3$ receptors may also play a role in the weight gain associated with antipsychotic medication. Histamine signaling is auto-regulated by the presynaptic H3-histamine receptor, which inhibits histamine synthesis and release when activated (128-130). Both H1-receptor agonists and H3-receptor antagonists have been investigated as anti-obesity therapeutics. However, most attention has focused on the development of antagonists for the H3receptor, since these are expressed almost exclusively in the central nervous system. Several compounds have been synthesized; examples are given in (128) and (129). In preclinical testing, the selective H3-receptor antagonist, A331440 (Fig. 11), at oral dosages of $5 \mathrm{mg} / \mathrm{kg}$ and $15 \mathrm{mg} / \mathrm{kg}$ twice daily, induced significant weight loss in mice (111).

Another example is HPP404 from Transtech Pharma (http://www.ttpharma.com), which is also reported to be in phase I. Many other H3 antagonists are in clinical development for indications different from obesity $(128,129)$. The H3 antagonist SCH-497079, which was acquired by Merck\&Co, has undergone phase II testing for weight management, but its status is presently unknown. The compound betahistine (Histalean ${ }^{\circledR}$, Fig. 11), which is on the market in Canada and Europe for vertigo, has also been claimed to decrease food intake via blockade of

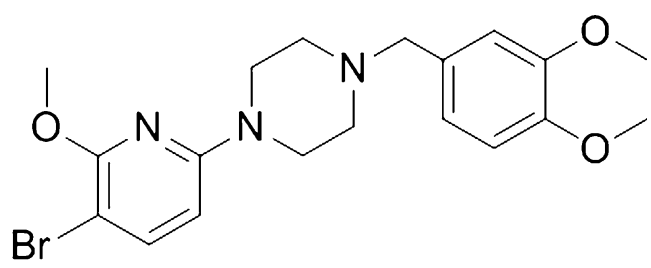

\section{NGD-4715}

Fig. 10 Structure of NGD-47 I 5, a MCH-RI antagonist presently in phase II. 
$\mathrm{H}_{3} \mathrm{C}$

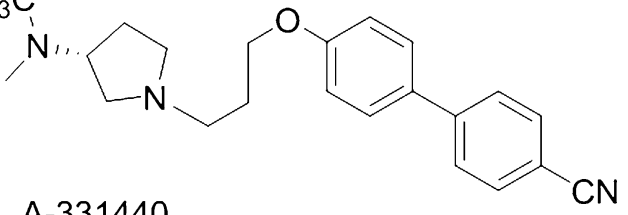

A-331440

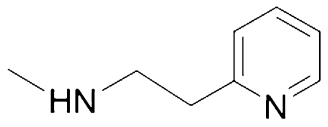

betahistine

Fig. I I Structures of the selective H3-receptor antagonist, A-33/440 and of betahistine.

central $\mathrm{H} 1$ and $\mathrm{H} 3$ receptors. However, consistent evidence for efficacy in humans appears to be lacking(131).

\section{NPY Antagonists}

Neuropeptide Y (NPY) is a centrally acting orexigenic peptide that belongs to the same (pancreatic polypeptide-) family as PYY and PP. Signaling at neuronal Y1 and Y5 receptors produces the orexigenic effects of NPY, whereas Y2- and Y4-receptor signaling produces an anorexic phenotype due to pre-synaptic inhibition of NPY release. The latter two receptors are also the targets of the gut hormones PYY, PP and their mimetics that have been discussed in a previous section. Exploring the potential utility of the Y1 and Y5 receptors as targets, several smallmolecule antagonists have been synthesized, for example by the Merck laboratories (124). An orally active Y5-receptor antagonist from Merck (MK-0557) was as unable to induce clinically meaningful weight loss in a one-year clinical trial (111). However, the Y5-receptor antagonist velneperit (S2367, Fig. 12) from Shionogi (http://www.shionogi.co.jp) is still in development. In a phase II trial, it showed modest but significant effects (111).

\section{Agouti-Related Protein (AgRP)- Inhibitors}

Similar to NPY, AgRP is an endogenous orexigenic protein acting in the basal hypothalamus. Consequently, selective<smiles>CC(C)(C)S(=O)(=O)C[C@H]1CC[C@H](C(=O)Nc2ccc(C(F)(F)F)cn2)CC1</smiles>

velneperit

Fig. I2 Chemical structure of velneperit, a Y5-receptor antagonist. inhibitors might also have potential in inhibiting food intake. However, there do not seem to be many candidates in advanced stages of development. An exception is TTP435 from Transtech Pharma (http://www.ttpharma. com), which is reported to be a selective inhibitor of AgRP with oral activity and high brain penetration. Following successful animal studies, the compound is currently in phase II clinical trials.

\section{Other CNS Compounds and Targets}

A possible future target for weight management could become the bombesin receptor subtype 3 (BRS-3). This is a GPCR which is widely distributed in the brain but whose natural ligand is still unknown. Recently, a group of scientists from Merck reported the synthesis of a BRS-3 agonist that reduced food intake and increased metabolic rate in mice (132).

\section{Inhibitors of Protein Tyrosine Phosphatase (PTPIB)}

This enzyme is widely expressed throughout the body. In the brain, it negatively regulates leptin signaling and appears to be involved in the development of leptin resistance (133). As leptin resistance plays a role in obesity, inhibition of central PTP1B activity may provide a way to overcome this. In addition, peripheral PTP1B inhibition might improve insulin sensitivity in muscle and liver. Recently, Banno et al. (133) showed that PTP1B plays an important role in POMC neurons in the hypothalamus. The natural compound trodusquemine (Fig. 13) is a central and peripheral inhibitor of PTP1B. It showed weight loss and beneficial effects on fasting blood glucose, blood cholesterol and triglyceride levels in obese animals (134-136).

The compound has been in development as MSI-1436 by Genaera, who ended phase I clinical studies in 2007. Since this company has ended its business, its current status and perspective are unclear, although the compound is used as experimental tool.

\section{COMPOUNDS AIMING TO REDUCE FAT MASS}

In addition to reducing energy intake, different pharmacological approaches are being evaluated to reach weight reduction or improve health by increasing energy expenditure or by reducing or redistributing adipose tissue. The latter may be useful to change "risky" (visceral) fat into less risk-bearing fat depots. In the food supplement area, there are many preparations claiming to help "burn" fat. Although some compounds, including caffeine, ephedrine and epigallocatechin gallate (EGGG), have been shown to possess some activity, sustained effects are generally 
Fig. 13 Structure of trodusquiemine, a natural PTP-IB inhibitor.<smiles>CC(C)[C@H](CCCC1CC[C@]2(C)C1CC[C@@]1(C)C2(C)[C@H](O)C[C@]2(C)C[C@@H](NCCCNCCCCNCCCN)CC[C@@]21C)OS(=O)(=O)O</smiles>

trodusquemine disappointing (37). Nevertheless, targeting energy expenditure (cellular bioenergetics), in particular adaptive thermogenesis, is regarded as a valuable option (137). Adaptive thermogenesis is generated by mitochondria of skeletal muscle and by brown adipose tissue (BAT) in response to external stimuli. Until five years ago, it was generally assumed that adult humans possess negligible amounts of BAT, which did not make this tissue an interesting option for pharmacological intervention. However, recent findings have demonstrated that adults maintain active BAT (138-140). As a result, interest in BAT as a new target for human obesity has also returned $(137,141,142)$.

Examples of the rather heterogeneous group of compounds targeting local or total body fat are listed in Table IV.

\section{Beta-3 Receptor Agonists}

The $\beta 3$-adrenergic receptor is expressed in adipocytes and some other tissues. The discovery, during the early 80s, of last century, of its role as a regulator of lipolysis and fatty acid oxidation in rodents pushed many pharmaceutical companies to start developing $\beta_{3} \mathrm{AR}$ agonists for human weight management (141). However, clinical studies in humans did not meet the high expectations.

For example, the selective human $\beta_{3}$-agonist, L-796568 (Fig. 14) failed to reduce weight or 24-h energy expenditure

Table IV Main Classes of Compounds Acting on Local or Total Body Fat

- Beta-3 adrenergic receptor agonists

- Selective thyroid hormone receptor subtype $\beta$-agonists

- Growth hormone analogues

- I I- $\beta$-Hydroxysteroid dehydrogenase type I ( I $\beta$-HSD I) inhibitors

- Sirtuin I activators

- Diazoxide

- Inihibitors of angiogenisis

- TGR5 agonists over 28 days in overweight men (143). Similarly, no clear effects of the $\beta_{3}$-agonist compound TAK-377 (Fig. 14) were found in a human trial (144). Recently, the development of a combination of the $\beta_{3}$ agonist L-377604 plus subitramine was terminated. Compound KRP-204 (Fig. 14) appears to be still in development for obesity (and also for other indications), but its present status is unclear.

Some other $\beta_{3}$ agonists, for example SR58611A (Fig. 14) from Sanofi-Aventis, are now being investigated for use in anxiety and depression. The lack of efficacy of $\beta 3$ agonists on human adipose tissue has been explained by the low numbers of $\beta 3$-adrenoreceptors on human adipocytes as compared to mice or the weak effect of $\beta 3$ activation on lipolysis in general. Furthermore, many compounds suffered from poor selectivity and unfavorable PK properties, such as a low oral bioavailability (141). However, the recent developments in the discovery of brown adipose tissue in humans expressing the $\beta 3 \mathrm{AR}$ have generated new optimism (137). There are indications that treatment with $\beta 3 \mathrm{AR}$ agonists may increase the amount and activity of this brown adipose tissue (141).

\section{Selective Thyroid Hormone Mimetics}

Thyroid hormone itself stimulates adaptive thermogenesis and lipolysis, but its use as anti-obesity compound is obsolete due to the many side effects, including tachycardia, muscle wasting and loss of bone mass. However, a number of selective thyroid hormone receptor (TR) subtype $\beta$ agonists have been developed that may have potential as anti-obesity and/or lipid-lowering agents. These include KB-141 (eprotirome, Fig. 15), GC-1 (sobetirome, Fig. 15), KB-2115 and MB07811.

These molecules possess pharmacological profiles different from that of thyroid hormone (145-147). For example, KB-141 was shown to have anti-obesity, lipid-lowering and anti-diabetic effects in rodents, without causing tachycardia. This suggests that selective $\operatorname{TR} \beta$ activation could provide a future strategy to attenuate features of the metabolic 
Fig. 14 Structures of some $\beta_{3}$ adrenergic agonists investigated as anti-obesity compounds.<smiles>O=S(=O)(Nc1ccc(CCNC[C@H](O)c2cccnc2)cc1)c1ccc(-c2nc(-c3ccc(C(F)(F)F)cc3)cs2)cc1</smiles>

L-796568<smiles>CCOC(=O)COc1ccc2c(c1)C[C@@H](NC[C@H](O)c1cccc(Cl)c1)CC2</smiles>

SR 58611A<smiles>[R6][R20]#[R]</smiles><smiles>C[C@H](CN[C@H](O)c1cccc(Cl)c1)Cc1c[nH]c2c(OCC(=O)O)cccc12</smiles>

TAK-377 (AJ-9677)

syndrome (145). However, more studies are needed to determine the therapeutic potential of this class, and there appear to be no compounds having progressed beyond phase I clinical trials at the moment (146).

\section{Growth Hormone (GH) Analogues}

The concept of using GH or its analogues to combat obesity dates back several years. It was based on different principles, including lower $\mathrm{GH}$ levels and a reduced responsiveness to $\mathrm{GH}$ in obese persons, which is generally restored after weight loss (111). However, when combined with a hypocaloric diet, GH was not shown to have additional benefits. In combination with an isoenergetic diet, GH induced only a modest reduction in weight as compared with placebo. Furthermore, several studies reported a worsening of insulin resistance in subjects treated with GH. A modified fragment of human GH, AOD9604, has been in development for weight management. It had been designed to mimic the lipolytic effects of GH without producing growth effects. However, its development was stopped in 2007 because of insufficient efficacy during a 24week trial with 536 subjects. Taken together, there seems to be little enthusiasm left for $\mathrm{GH}$ as a target to reduce body weight.

\section{Inhibition of I I-B Hydroxysteroid Dehydrogenase Type I}

The 11- $\beta$ hydroxysteroid dehydrogenase enzymes type 1 isoform (11 $\beta$-HSD1) is currently receiving considerable attention because of its possible role in the development of the metabolic syndrome (148-152). This is amongst others based on the observation that overlap exists in patho-physiology and symptomology between Cushing syndrome and the metabolic complications of visceral obesity. The enzyme $11 \beta$-HSD1 primarily catalyzes the reduction of hormonally inactive cortisone into the high- 
<smiles>N[C@@H](Cc1cc(I)c(Oc2ccc(O)c(I)c2)c(I)c1)C(=O)O</smiles><smiles>CC(C)c1cc(Oc2c(Cl)cc(CC(=O)O)cc2Cl)ccc1O</smiles>

KB-141 (eprotirome)<smiles>Cc1cc(OCC(=O)O)cc(C)c1Cc1ccc(O)c(C(C)C)c1</smiles>

Fig. I5 Chemical structures of thyroid hormone (T3) and 2 selective thyroid hormone receptor (TR) subtype $\beta$-agonists developed as antiobesity and/or lipid-lowering agents.

affinity ligand cortisol (or corticosterone in rodents) $(150,151)$. It is rather ubiquitously expressed throughout the body, with highest levels in the liver followed by adipose tissue and brain. Several natural compounds of both endogenous and exogenous origin are known inhibitors of $11 \beta$-HSD1, including glycyrrhetinic acid from licorice root and its synthetic hemisuccinyl ester, carbenoxolone (151). However, most of these are unspecific, whilst enzyme and also tissue specificity would be important prerequisites for therapeutic usefulness in obesity and/or its metabolic complications. Selective $11 \beta$ - HSD1 inhibitors that are effective in adipose tissue have shown positive results in animal models and may also be efficacious in improving insulin sensitivity and reducing weight in humans (150152). Several companies, including Biovitrum, Amgen, AstraZeneca, Abbott, Merck, Pfizer, and Incyte have developed 11ß-HSD1 inhibitors, mainly for treatment of type 2 diabetes but also for obesity (153-155). Some structures are given in Fig. 16.

Although the development of the first selective $11 \beta$ HSD1 inhibitor BVT-3498 (AMG-331) was terminated during phase II testing, several other compounds have reached the clinical phase. One of the most advanced is INCB 13739 (structure not disclosed) from Incyte (156). The next few years will be pivotal in showing whether this target will be successful. The need for selectivity and the risk of activation of the HPA axis have been suggested as potential hurdles (154).

\section{Sirtuin I as Potential Target in Obesity}

SIRT1 belongs to the silent information regulator 2 (Sir2) enzymes (or sirtuins) which have emerged as central players in the regulation of critical metabolic pathways, such as insulin secretion and lipid metabolism. Sirtuins regulate their targets by modulating the activity of their partner proteins through reversible de-acetylation. The most studied sirtuin is SIRT1 (see for example (157) and (158) for recent reviews). This enzyme has been implicated in longevity and the beneficial effects of caloric restriction. SIRT1 enhances fat mobilization and lipolysis by binding to and repressing the expression of PPAR $\gamma$-regulated genes, including those mediating fat storage. In addition, SIRT1 interacts with PGC-1 $\alpha$, inducing the expression of mitochondrial genes involved in oxidative metabolism and fatty acid oxidation. Resveratrol (Fig. 17) has been proposed as a natural SIRT1 activator, in addition to having other activities.

Following the discovery of SIRT1 and its role in metabolism, several small-molecule SIRT1 activators (some examples given in Fig. 17) have been synthesized with structures different from that of resveratrol but with considerably higher potency $(159,160)$. A number of these compounds were reported to improve metabolic function in animal models of diabetes and obesity, suggesting that they may have therapeutic potential. For example, SIRT 1720 (Fig. 17) was found to protect mice against diet-induced obesity by enhancing oxidative metabolism in skeletal muscle, liver and BAT (161).

In 2004, GlaxoSmithKline founded Sirtris Pharmaceuticals, a company focusing on the development of drugs targeting SIRT1. Sirtris reports a number of compounds in clinical development (162). However, recently Pacholec et al. (163) suggested that resveratrol and a number of the Sirtris compounds are not directly activating SIRT1. The authors also questioned the beneficial effects of SRT1720 in a rodent diabetes model and stated that the Sirtris compounds and resveratrol are highly promiscuous compounds having multiple targets. Similar to several other classes described in this review, the coming years will show whether the high expectations are justified.

\section{Diazoxide}

Diazoxide (Fig. 18) is a potassium channel activator that opens the $\mathrm{K}+$ - ATP channels in pancreatic $\beta$-cells, thereby inhibiting insulin secretion. Diazoxide is currently used to treat hypoglycemia but may also have potential in hypertriglyceridemia and obesity.

Although some investigators suggest a beneficial effect of diazoxide in obesity in combination with caloric restriction and physical exercise (164), its usefulness as a target in obesity is questioned by others (165). A controlled release 
Fig. 16 Examples of some II $\beta$ -

HSDI inhibitors.

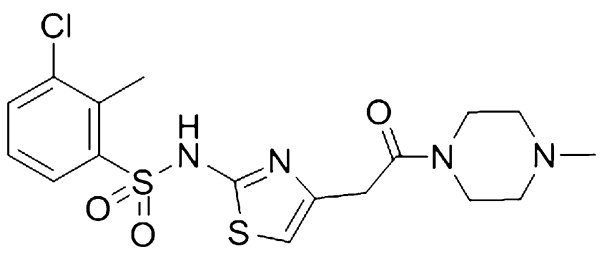

BVT2733

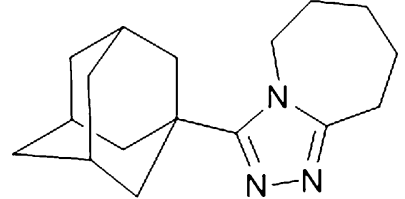

MK544

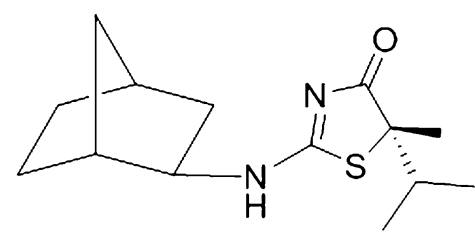

AMG-221<smiles>N#Cc1ccc(-c2ccc(S(=O)(=O)Nc3cccc(N)n3)cc2)cc1</smiles>

PF-915275

formulation of its choline salt is under development by Essential Therapeutics (http://essentialistherapeutics.com/ pages/products.php).

\section{Angiogenesisis Inhibitors}

Adipose tissue is highly vascularized, and expansion requires the formation of new capillaries. Therefore, the use of selective inhibitors of angiogenisis has been proposed as a possible approach to reduce fat tissue $(149,166,167)$. An interesting proof-of-concept study in mice was described by Rupnick et al. (166), who showed that systemic antiangiogenic agents caused dose-dependent, reversible weight reduction and adipose tissue loss. However, an important challenge is to target adipose tissue resulting in "magic bullets" that "melt fat" (168). This principle was shown by Kolonin et al. (169) using a phage-display method in mice. Molecular targets could include one or several of the angiogenic factors secreted by adipocytes including leptin, angiopoietins, HGF, GM-CSF, VEGF, FGF-2, and TGF- $\beta$ (170). One of the companies active in this area is Korean AngioLab (http://angiolab.co.kr/), who reports to develop a herbal preparation named ALSL1023 for this purpose.

\section{TGR5}

TGR5 is a G-protein coupled receptor that is activated by bile acids, including lithocholic acid and deoxycholic acid (171). TGR5 is widely expressed in the body, in particular in metabolic tissues such as liver, muscle, intestine, and brown adipose tissue. Interest in TGR 5 as potential target for obesity and diabetes has been raised, since receptor activation was shown to be connected with an increase in energy expenditure, a reduction of diet-induced obesity and an increase of GLP-1 release in vitro $(172,173)$. A number of companies have started to synthesize and test selective TGR5 agonists, with bile acid-derived or non-bile acid structures $(171,174)$. One of these is the semi-synthetic TGR5 agonist INT-777, which was found to increase energy expenditure and reduce weight gain in mice on a high-fat diet (173). Furthermore, insulin sensitivity in obese mice was improved with INT-777. The development of TGR5 agonists is still in its infancy, and although results so far look promising, it is too early to draw conclusions on the potential of this target. There are no drug candidates yet that have reached the clinical phase. As TGR5 seems to be involved in a rather broad range of processes (171), more insight in potential off-target effects will also be needed. 
Fig. 17 Chemical structure of resveratrol and 3 first generation small-molecule SIRTI activators.
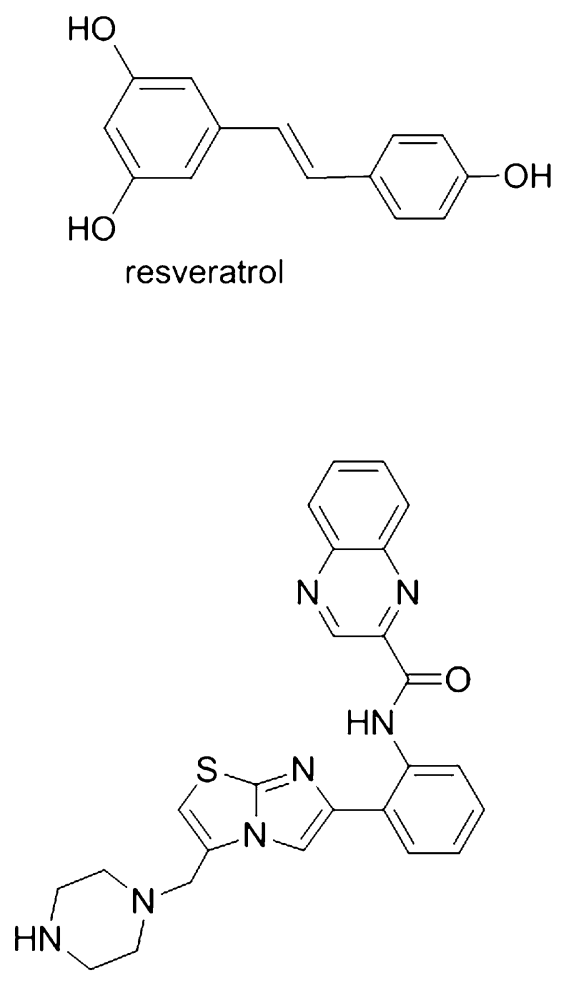

SIRT 1720

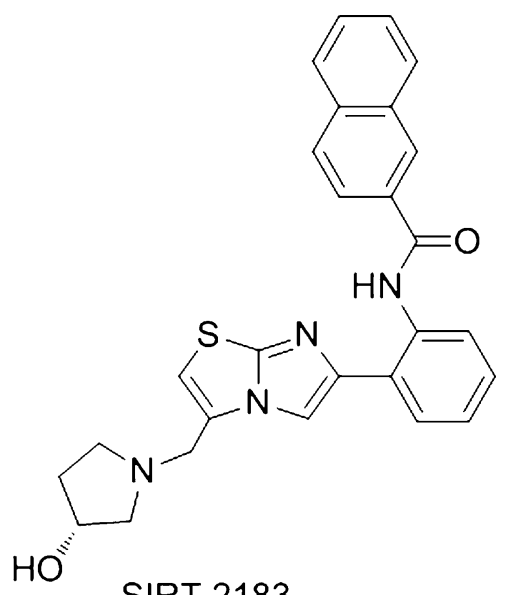

SIRT 2183<smiles>COc1cc(C(=O)Nc2ccccc2-c2cn3c(CN4CCNCC4)csc3n2)cc(OC)c1OC</smiles>

SIRT 1460

\section{CONCLUSIONS}

The rising obesity figures and associated health complications present unmet medical needs for safe and effective new drug therapies. As illustrated in this review, a remarkably wide diversity of targets and compounds is presently being investigated. Despite the failures of the past, for example with rimonabant and its analogues, industry is prepared to take considerable risks. Remarkably, combinations of existing CNS drugs (topiramate, zonisa-

Fig. 18 Chemical structure of diazoxide.

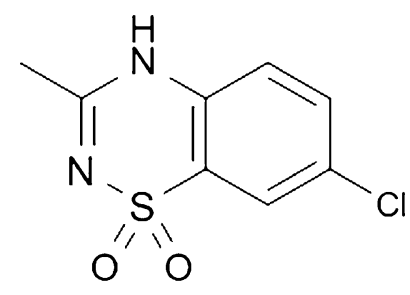

diazoxide mide, phentermine and bupropion) are among the most advanced in development. In general and in spite of the risks for side effects, CNS targets, including 5-HT, H3 and Y-receptors, continue to be considered as promising. This is amongst others due to the fact that for the time being the largest effects are expected from central intervention. Compounds acting on peripheral targets might offer advantages in terms of side effects. Apart from the GLP-1 analogues liraglutide and exenatide and the combination of pramlintide with metraleptin, peptide drugs mimicking satiety hormones have not met the expectations so far. However, better oral, intranasal, and transdermal formulations could help to enhance the efficacy of such approaches. Among the targets within the gut, those that stimulate the release of GLP-1 seem to be the most promising at the moment. Of particular interest is the GPR119 receptor. As also described in this review, the endocannabinoid system as target may see a revival during the coming years. Being an alternative to what is currently the only worldwide approved 
lipase inhibitor drug orlistat, the development of new lipase inhibitor cetilistat seems to be one of the least risky. Other approaches, such as MTP inhibition, need further proof of principle. The value of other potential targets in the battle against obesity, including $11 \beta$-HSD1, SIRT 1, TGR 5 and the modulation of intestinal flora, will become clear during the coming few years. Combination therapies, possibly including drug-food combinations, not only offer the advantage of multi-target therapy with sometimes higher efficacy, but may also reduce side effects and risks. In particular, for the preparations acting within the CNS, the coming years will be crucial to see whether side effects remain acceptable. Looking at the history of weight loss drugs, it is understandable that authorities will be watchful. Obesity is not regarded as a life-threatening disease, and, if effective, anti-obesity drugs will be prescribed to a large and diverse group of people. Furthermore, considerable offlabel use and distribution via the Internet and other channels is to be expected. Given the high activity in this field of research and notwithstanding the possible risks for failures, it seems obvious that the therapeutic arsenal of weight management drugs and other compounds used in obesity will change considerably in the coming five years.

Open Access This article is distributed under the terms of the Creative Commons Attribution Noncommercial License which permits any noncommercial use, distribution, and reproduction in any medium, provided the original author(s) and source are credited.

\section{REFERENCES}

1. Bessesen DH. Update on obesity. J Clin Endocrinol Metab. 2008;93:2027-34.

2. James WPT. The epidemiology of obesity: the size of the problem. J Intern Med. 2008;263:336-52.

3. Wang Y, Beydoun MA, Liang L, Caballero B, Kumanyika SK. Will all Americans become overweight or obese? Estimating the progression and cost of the US obesity epidemic. Obesity. 2008;16:2323-30.

4. Despres J-P, Lemieux I. Abdominal obesity and metabolic syndrome. Nature. 2006;444:881-7.

5. Grundy SM, Cleeman JI, Daniels SR, et al. Diagnosis and management of the metabolic syndrome: an American Heart Association/National Heart, Lung, and Blood Institute scientific statement. Circulation. 2005;112:2735-52.

6. Haslam DW, James WP. Obesity. Lancet. 2005;366:1197-209.

7. Fox CS, Massaro JM, Hoffmann U, et al. Abdominal visceral and subcutaneous adipose tissue compartments: association with metabolic risk factors in the framingham heart study. Circulation. 2007;116:39-48.

8. Kuk JL, Katzmarzyk PT, Nichaman MZ, Church TS, Blair SN, Ross R. Visceral fat is an independent predictor of all-cause mortality in men. Obesity. 2006; 14:336-41.

9. Behn A, Ur E. The obesity epidemic and its cardiovascular consequences. Curr Opin Cardiol. 2006;21:353-60.
10. Han TS, Sattar N, Lean M. Assessment of obesity and its clinical implications. Br Med J. 2006;333:695-8.

11. O’Donovan G, Thomas EL, McCarthy JP, et al. Fat distribution in men of different waist girth, fitness level and exercise habit. Int J Obes. 2009;33:1356-62.

12. Romero-Corral A, Somers VK, Sierra-Johnson J, et al. Normal weight obesity: a risk factor for cardiometabolic dysregulation and cardiovascular mortality. Eur Heart J. 2010;31:737-46.

13. Hotamisligil GS. Inflammation and metabolic disorders. Nature. 2006;444:860-7.

14. Shoelson SE, Herrero L, Naaz A. Obesity, inflammation, and insulin resistance. Gastroenterology. 2007;132:2169-80.

15. Guilherme A, Virbasius JV, Puri V, Czech MP. Adipocyte dysfunctions linking obesity to insulin resistance and type 2 diabetes. Nat Rev Mol Cell Biol. 2008;9:367-77.

16. Mittra S, Bansal VS, Bhatnagar PK. From a glucocentric to a lipocentric approach towards metabolic syndrome. Drug Discov Today. 2008;13:211-8.

17. Fleischman A, Shoelson SE, Bernier R, Goldfine AB. Salsalate improves glycemia and inflammatory parameters in obese young adults. Diab Care. 2008;31:289-94.

18. Hotamisligil GS, Erbay E. Nutrient sensing and inflammation in metabolic diseases. Nat Rev Immunol. 2008;8:923-34.

19. Shoelson SE, Goldfine AB. Getting away from glucose: fanning the flames of obesity-induced inflammation. Nat Med. 2009;15:373-4.

20. Nedungadi TP, Clegg DJ. Sexual dimorphism in body fat distribution and risk for cardiovascular diseases. J Cardiovasc Transl Res. 2009;2:321-7.

21. Rebuffe-Scrive M, Andersson B, Olbe L, Bjorntorp P. Metabolism of adipose tissue in intraabdominal depots of nonobese men and women. Metabolism. 1989;38:453-8.

22. McLaughlin TM, Liu T, Yee G, et al. Pioglitazone increases the proportion of small cells in human abdominal subcutaneous adipose tissue. Obesity. 2010;18:926-31.

23. Janiszewski PM, Ross R. The utility of physical activity in the management of global cardiometabolic risk. Obesity. 2009;17.

24. Johnson NA, Sachinwalla T, Walton DW, et al. Aerobic exercise training reduces hepatic and visceral lipids in obese individuals without weight loss. Hepatology. 2009;50:1105-12.

25. Ross R, Bradshaw AJ. The future of obesity reduction: beyond weight loss. Nat Rev Endocrinol. 2009;5:319-26.

26. Goodyear LJ. The exercise pill - too good to be true? N Engl J Med. 2008;359:1842-4.

27. Himms-Hagen J. Exercise in a pill: feasibility of energy expenditure targets. Curr Drug Targets CNS Neurol Disord. 2004;3:389-409.

28. Narkar VA. AMPK and PPARס agonists are exercise mimetics. Cell. 2008;134:405-15.

29. Berridge KC, Ho CY, Richard JM, DiFeliceantonio AG. The tempted brain eats: Pleasure and desire circuits in obesity and eating disorders. Brain Res. 2010.

30. Halford JCG, Boyland EJ, Blundell JE, Kirkham TC, Harrold JA. Pharmacological management of appetite expression in obesity. Nat Rev Endocrinol. 2010;6:255-69.

31. Mela DJ. Eating for pleasure or just wanting to eat? Reconsidering sensory hedonic responses as a driver of obesity. Appetite. 2006;47:10-7.

32. Adan RAH, Vanderschuren LJMJ, la Fleur SE. Anti-obesity drugs and neural circuits of feeding. Trends Pharmacol Sci. 2008;29:208-17.

33. Cota D, Tschöp MH, Horvath TL, Levine AS. Cannabinoids, opioids and eating behavior: the molecular face of hedonism? Brain Res Rev. 2006;51:85-107.

34. Bult MJF, van Dalen T, Muller AF. Surgical treatment of obesity. Eur J Endocrinol. 2008;158:135-45. 
35. Couzin J. Medicine: bypassing medicine to treat diabetes. Science. 2008;320:438-40.

36. Rothman RB, Baumann MH. Appetite suppressants, cardiac valve disease and combination pharmacotherapy. Am $\mathrm{J}$ Ther. 2009; 16:354-64

37. Witkamp RF. Biologically active compounds in food products and their effects on obesity and diabetes. Comprehensive natural products II. Oxford: Elsevier; 2010. p. 509-45.

38. Birari RB, Bhutani KK. Pancreatic lipase inhibitors from natural sources: unexplored potential. Drug Discov Today. 2007;12:879-89.

39. FDA. Early communication about an ongoing safety review Orlistat (marketed as Alli and Xenical). 2009. http://www.fda.gov/Drugs/ DrugSafety/PostmarketDrugSafetyInformationforPatientsandPro viders/DrugSafetyInformationforHeathcareProfessionals/ ucm 179166.

40. Kopelman P, De Groot GH, Rissanen A, et al. Weight loss, HbA 1c reduction, and tolerability of cetilistat in a randomized, placebo-controlled phase 2 trial in obese diabetics: comparison with orlistat (xenical). Obesity. 2010;18:108-15.

41. Hussain MM, Bakillah A. New approaches to target microsomal triglyceride transfer protein. Curr Opin Lipidol. 2008;19:572-8.

42. Van Gaal L, Vercruysse F, Wajs E, Xie J, Ways D, van Nueten L. JNJ-16269110, an enterically targetted microsomal triglyceride transfer protein inhibitor, lowers body weight in overweight/ obese subjects. Obes Rev. 2010;11(supplement s1):42.

43. Chen HC, Farese Jr RV. Inhibition of triglyceride synthesis as a treatment strategy for obesity: lessons from DGAT1-deficient mice. Arterioscler Thromb Vasc Biol. 2005;25:482-6.

44. Shi YG, Cheng D. Beyond triglyceride synthesis: the dynamic functional roles of MGAT and DGAT enzymes in energy metabolism. Am J Physiol Endocrinol Metab. 2009;297:E10-8.

45. AstraZeneca. Pipepline summary 2010; http://www.astraze neca.com/research/our-pipeline-summary/. Access date August $15,2010$.

46. Idris I, Donnelly R. Sodium-glucose co-transporter-2 inhibitors: an emerging new class of oral antidiabetic drug. Diab Obes Metab. 2009;11:79-88.

47. Johnson \& Johnson. Pharmaceutical pipeline - recent approvals/ potential filings. Selective highlights as of 7/20/2010. http:// files.shareholder.com/downloads/JNJ/990821560x0x387659/ f0fa5052-2cba-4402-91ab-b40b1fbd5e76/Q22010pipeline.pdf.

48. Ley RE, Turnbaugh PJ, Klein S, Gordon JI. Microbial ecology: human gut microbes associated with obesity. Nature. 2006;444:1022-3.

49. Turnbaugh PJ, Ley RE, Mahowald MA, Magrini V, Mardis ER, Gordon JI. An obesity-associated gut microbiome with increased capacity for energy harvest. Nature. 2006;444:1027-31.

50. Thuny F, Richet H, Casalta J-P, Angelakis E, Habib G, Raoult D. Vancomycin treatment of infective endocarditis is linked with recently acquired obesity. PLoS ONE. 2010;5:e9074.

51. Engelstoft MS, Egerod KL, Holst B, Schwartz TW. A gut feeling for obesity: 7TM sensors on enteroendocrine cells. Cell Metab. 2008;8:447-9.

52. Delzenne N, Blundell J, Brouns F, et al. Gastrointestinal targets of appetite regulation in humans: ILSI Supplement. Obes Rev. 2010;11:234-50.

53. Torres SJ, Nowson CA. Relationship between stress, eating behavior, and obesity. Nutrition. 2007;23:887-94.

54. Cummings DE, Overduin J. Gastrointestinal regulation of food intake. J Clin Invest. 2007;117:13-23.

55. Obici S. Molecular targets for obesity therapy in the brain. Endocrinology. 2009;150:2512-7.

56. Neary MT, Batterham RL. Gut hormones: implications for the treatment of obesity. Pharmacol Ther. 2009;124:44-56.

57. Yan KS, Pasricha PJ. Acting in good taste: nutrient sensors in the gut. Gut. 2009;58:897-8.
58. Young RL, Sutherland K, Pezos N, et al. Expression of taste molecules in the upper gastrointestinal tract in humans with and without type 2 diabetes. Gut. 2009;58:337-46.

59. Yoshida R, Ohkuri T, Jyotaki M, et al. Endocannabinoids selectively enhance sweet taste. Proc Natl Acad Sci. 2010;107:935-9.

60. Cox HM, Tough IR, Woolston A-M, et al. Peptide YY is critical for acylethanolamine receptor GPR119-induced activation of gastrointestinal mucosal responses. Cell Metab. 2010;1 1:532-42.

61. Alpers DH. Nutrient sensing in de gastrointestinal tract. Curr Opin Gastroenterol. 2010;26:134-9.

62. Hansen HS, Diep TA. N-acylethanolamines, anandamide and food intake. Biochem Pharmacol. 2009;78:553-60.

63. Izzo AA, Sharkey KA. Cannabinoids and the gut: new developments and emerging concepts. Pharmacol Ther. 2010;126:2138

64. Lan H, Vassileva G, Corona A, et al. GPR119 is required for physiological regulation of glucagon-like peptide- 1 secretion but not for metabolic homeostasis. J Endocrinol. 2009;201:219-30.

65. Lauffer LM, Iakoubov R, Brubaker PL. GPR119 is essential for oleoylethanolamide-induced glucagon-like peptide-1 secretion from the intestinal enteroendocrine L-cell. Diabetes. 2009;58:1058-66.

66. Yang Y, Chen M, Georgeson KE, Harmon CM. Mechanism of oleoylethanolamide on fatty acid uptake in small intestine after food intake and body weight reduction. Am J Physiol Regul Integr Comp Physiol. 2007;292:R235-41.

67. Overton HA, Babbs AJ, Doel SM, et al. Deorphanization of a G protein-coupled receptor for oleoylethanolamide and its use in the discovery of small-molecule hypophagic agents. Cell Metab. 2006;3:167-75.

68. Fyfe MCT, Overton HA, Procter MJ, Reynet C, White JR. Chapter 9: new nonpeptide-binding GPCRs as targets for diabetes and the metabolic syndrome. Annu Rep Med Chem. 2007;129-45.

69. Overton HA, Fyfe MCT, Reynet C. GPR119, a novel G protein-coupled receptor target for the treatment of type 2 diabetes and obesity. Br J Pharmacol. 2008;153:S76-81.

70. Jones RM, Leonard JN, John EM. Chapter 7 the emergence of GPR119 agonists as anti-diabetic agents. Annual Reports in Medicinal Chemistry: Academic Press; 2009:149-70.

71. Semple G, Fioravanti B, Pereira G, et al. Discovery of the first potent and orally efficacious agonist of the orphan G-protein coupled receptor 119. J Med Chem. 2008;51:5172-5.

72. Wu Y, Kuntz JD, Carpenter AJ, et al. 2, 5-Disubstituted pyridines as potent GPR119 agonists. Bioorg Med Chem Lett. 2010;20:2577-81.

73. Arena Pharmaceuticals. APD597 for type 2 diabetes. Accessed August 20, 2010. http://www.arenapharm.com/apd597.aspx? $\mathrm{p}=2.6$.

74. Metabolex. Metabolex and Sanofi-Aventis enter into an agreement for novel type2 diabetes treatment. Accessed August 10, 2010. http://www.metabolex.com/news/jun252010.html.

75. Cota D. The role of the endocannabinoid system in the regulation of hypothalamic-pituitary-adrenal axis activity. J Neuroendocrinol. 2008;20:35-8.

76. Di Marzo V, Després JP. CB1 antagonists for obesity; what lessons have we learned from rimonabant? Nat Rev Endocrinol. 2009;5:633-8.

77. Piazza PV, Lafontan M, Girard J. Integrated physiology and pathophysiology of CB1-mediated effects of the endocannabinoid system. Diabetes Metabol. 2007;33:97-107.

78. Jones D. End of the line for cannabinoid receptor 1 as an antiobesity target? Nat Rev Drug Discov. 2008;7:961-2.

79. Bermudez-Silva FJ, Viveros MP, McPartland JM, Rodriguez de Fonseca F. The endocannabinoid system, eating behavior and 
energy homeostasis: the end or a new beginning? Pharmacol Biochem Behav. 2010;95:375-82.

80. Pavon FJ, Serrano A, Perez-Valero V, et al. Central versus peripheral antagonism of cannabinoid $\mathrm{CB} 1$ receptor in obesity: effects of LH-21, a peripherally acting neutral cannabinoid receptor antagonist, in Zucker rats. J Neuroendocrinol. 2008;20:116-23.

81. Sink K, Segovia K, Nunes E, et al. Intracerebroventricular administration of cannabinoid CB1 receptor antagonists AM251 and AM4113 fails to alter food-reinforced behavior in rats. Psychopharmacology (Berl). 2009;206:223-32.

82. Son MH, Kim HD, Chae YN, et al. Peripherally acting CB1receptor antagonist: the relative importance of central and peripheral $\mathrm{CB} 1$ receptors in adiposity control. Int $\mathrm{J}$ Obes. 2010;34:547-56.

83. Turu G, Hunyady L. Signal transduction of the CB1 cannabinoid receptor. J Mol Endocrinol. 2010;44:75-85.

84. Chen RZ, Frassetto A, Lao JZ, et al. Pharmacological evaluation of LH-21, a newly discovered molecule that binds to cannabinoid CB1 receptor. Eur J Pharmacol. 2008;584:338-42.

85. Receveur JM, Murray A, Linget JM, et al. Conversion of 4cyanomethyl-pyrazole-3-carboxamides into CB1 antagonists with lowered propensity to pass the blood-brain-barrier. Bioorg Med Chem Lett. 2010;20:453-7.

86. Fridberg M, Little PB, Cooper M, Jensen NO, Elling CE. A single ascending dose study of TM38837-a novel second generation peripheral selective $\mathrm{CB} 1$ receptor antagonist in health male volunteers. Obes Rev. 2010;10(supplement 1):180.

87. Moran TH, Dailey MJ. Gut peptides: targets for antiobesity drug development? Endocrinology. 2009;150:2526-30.

88. Chapman I, Parker B, Doran S, et al. Effect of pramlintide on satiety and food intake in obese subjects and subjects with type 2 diabetes. Diabetologia. 2005;48:838-48.

89. Ravussin E. Enhanced weight loss with pramlintide/metreleptin: an integrated neurohormonal approach to obesity pharmacotherapy. Obesity (Silver Spring). 2009;17:1736-43.

90. Takeda. Amylin and Takeda announce decision to advance development of Pramlintide/Metreleptin combination treatment for obesity. Accessed August 15 2010. http://www.takeda.com/ press/article_35851.html.

91. Batterham RL, Cohen MA, Ellis SM, et al. Inhibition of food intake in obese subjects by peptide YY3-36. N Engl J Med. 2003:349:941-8.

92. Boggiano MM, Chandler PG, Oswald KD, et al. PYY3-36 as an anti-obesity drug target. Obes Rev. 2005;6:307-22.

93. 7 TM Pharma. TM 30339 in gastrointestinal disorders. Accessed August 15, 2010 http://www.7tm.com/R-D/Gastrointestinal_ Disorders.aspx.

94. 7TM Pharma. Information on Obinepitide. Accessed August 15 2010. http://www.7tm.com/R-D/Metabolic_Disorders/Obine pitide.aspx.

95. Rosenthal J. Market watch: upcoming market catalysts in Q1 of 2010. Nat Rev Drug Discov. 2010;9:11.

96. Astrup A, Rössner S, Van Gaal L, et al. Effects of liraglutide in the treatment of obesity: a randomised, double-blind, placebocontrolled study. Lancet. 2009;374:1606-16.

97. Novo Nordisk. Novo Nordisk is developing an oral GLP-1 to increase the convenience of GLP-1 treatment of type 2 diabetes. Accessed August 20, 2010. http://www.novonordisk.com/press/ rd_pipeline/rd_pipeline.asp?showid $=19$.

98. Chandra R, Liddle RA. Cholecystokinin. Curr Opin Endocrinol Diab Obes. 2007;14:63-7.

99. Jordan J, Greenway FL, Leiter LA, et al. Stimulation of cholecystokinin-A receptors with GI181771X does not cause weight loss in overweight or obese patients. Clin Pharmacol Ther. 2008;83:281-7.
100. Cummings DE, Purnell JQ Frayo RS, Schmidova K, Wisse BE, Weigle DS. A preprandial rise in plasma ghrelin levels suggests a role in meal initiation in humans. Diabetes. 2001;50:1714-9.

101. Egecioglu E, Jerlhag E, Salomé N, et al. Ghrelin increases intake of rewarding food in rodents. Addict Biol. 2010;15:304-11.

102. Yang J, Zhao TJ, Goldstein JL, Brown MS. Inhibition of ghrelin O-acyltransferase (GOAT) by octanoylated pentapeptides. Proc Natl Acad Sci USA. 2008;105:10750-5.

103. Moulin A, Demange L, Bergé G, et al. Toward potent ghrelin receptor ligands based on trisubstituted 1,2, 4-triazole structure. 2. Synthesis and pharmacological in vitro and in vivo evaluations. J Med Chem. 2007;50:5790-806.

104. Salomé N, Hansson C, Taube M, et al. On the central mechanism underlying ghrelin's chronic pro-obesity effects in rats: new insights from studies exploiting a potent ghrelin receptor antagonist. J Neuroendocrinol. 2009;21:777-85.

105. Helmling S, Maasch C, Eulberg D, et al. Inhibition of ghrelin action in vitro and in vivo by an RNA-Spiegelmer. Proc Natl Acad Sci USA. 2004;101:13174-9.

106. Vizcarra JA, Kirby JD, Kim SK, Galyean ML. Active immunization against ghrelin decreases weight gain and alters plasma concentrations of growth hormone in growing pigs. Domest Anim Endocrinol. 2007:33:176-89.

107. Kleinridders A, Könner AC, Brüning JC. CNS-targets in control of energy and glucose homeostasis. Curr Opin Pharmacol. 2009;9:794-804.

108. Morton GJ, Cummings DE, Baskin DG, Barsh GS, Schwartz MW. Central nervous system control of food intake and body weight. Nature. 2006;443:289-95.

109. Valassi E, Scacchi M, Cavagnini F. Neuroendocrine control of food intake. NMCD. 2007;1-10.

110. Dwoskin LP, Rauhut AS, King-Pospisil KA, Bardo MT. Review of the pharmacology and clinical profile of bupropion, an antidepressant and tobacco use cessation agent. CNS Drug Rev. 2006;12:178-207.

111. Valentino MA, Lin JE, Waldman SA. Central and peripheral molecular targets for antiobesity pharmacotherapy. Clin Pharmacol Ther. 2010;87:652-62.

112. Astrup A, Madsbad S, Breum L, Jensen TJ, Kroustrup JP, Larsen TM. Effect of tesofensine on bodyweight loss, body composition, and quality of life in obese patients: a randomised, double-blind, placebo-controlled trial. Lancet. 2008;372:1906-13.

113. Vivus Incorporated. VIVUS announces positive results from two phase 3 studies; Obese patients on Qnexa achieve average weight loss up to $14.7 \%$ and significant improvements in comorbidities. Accessed August 10, 2010. http://ir.vivus.com/ releasedetail.cfm?ReleaseID $=407933$.

114. Gadde KM, Franciscy DM, Wagner HR, Krishnan KR. Zonisamide for weight loss in obese adults: a randomized controlled trial. JAMA. 2003;289:1820-5.

115. Orexigen. Orexigen therapeutics announces that contrave $(\mathrm{R})$ reduced depression scores and body weight in overweight and obese patients with major depression. Accessed August 15, 2010. http://ir.orexigen.com/phoenix.zhtml?c=207034\&p=irol-news Article\&ID $=1441841$ \&highlight $=$.

116. Garfield AS, Heisler LK. Pharmacological targeting of the serotonergic system for the treatment of obesity. J Physiol (Lond). 2009;587:49-60.

117. Vickers SP, Easton N, Webster LJ, et al. Oral administration of the $5-\mathrm{HT}_{2 \mathrm{C}}$ receptor agonist, mCPP, reduces body weight gain in rats over 28 days as a result of maintained hypophagia. Psychopharmacology (Berl). 2003;167:274-80.

118. Vickers SP, Dourish CT, Kennett GA. Evidence that hypophagia induced by d-fenfluramine and d-norfenfluramine in the rat is mediated by $5-\mathrm{HT}_{2 \mathrm{C}}$ receptors. Neuropharmacology. 2001;41:200-9. 
119. Heal DJ, Smith SL, Fisas A, Codony X, Buschmann H. Selective 5-HT6 receptor ligands: progress in the development of a novel pharmacological approach to the treatment of obesity and related metabolic disorders. Pharmacol Ther. 2008;117:207-31.

120. Smith SR. Lorcaserin (APD356), a selective 5-HT2C agonist, reduces body weight in obese men and women. Obesity (Silver Spring). 2009;17:494-503.

121. Arena Pharmaceuticals. Arena pharmaceuticals submits new drug application to FDA for lorcaserin for weight management. December 2009. http://invest.arenapharm.com/releases.cfm? Year $=\&$ Releases Type $=\&$ PageNum $=2$.

122. Thanos PK, Michaelides M, Ho CW, et al. The effects of two highly selective dopamine $\mathrm{D}_{3}$ receptor antagonists (SB-277011A and NGB-2904) on food self-administration in a rodent model of obesity. Pharmacol Biochem Behav. 2008;89:499-507.

123. Adan RA. The MC4 receptor and control of appetite. Br J Pharmacol. 2006;149:815-27.

124. Van der Ploeg LH. Design and synthesis of (ant)-agonists that alter appetite and adiposity. Prog Brain Res. 2006;153:107-18.

125. Jeon MK, Cheon HG. Promising strategies for obesity pharmacotherapy: Melanocortin-4 (MC-4) receptor agonists and melanin concentrating hormone $(\mathrm{MCH})$ receptor-1 antagonists. Curr Top Med Chem. 2009;9:504-38.

126. Krishna R, Gumbiner B, Stevens C, et al. Potent and selective agonism of the melanocortin receptor 4 with MK-0493 does not induce weight loss in obese human subjects: energy intake predicts lack of weight loss efficacy. Clin Pharmacol Ther. 2009;86:659-66

127. Méndez-Andino JL, Wos JA. MCH-R1 antagonists: what is keeping most research programs away from the clinic? Drug Discov Today. 2007;12:972-9.

128. Esbenshade TA, Fox GB, Cowart MD. Histamine H3 receptor antagonists: preclinical promise for treating obesity and cognitive disorders. Mol Interv. 2006;6:77-88.

129. Gemkow MJ, Davenport AJ, Harich S, Ellenbroek BA, Cesura A, Hallett D. The histamine H3 receptor as a therapeutic drug target for CNS disorders. Drug Discov Today. 2009;14:509-15.

130. Yoshimoto R, Miyamoto Y, Shimamura K, et al. Therapeutic potential of histamine $\mathrm{H} 3$ receptor agonist for the treatment of obesity and diabetes mellitus. Proc Natl Acad Sci. 2006;103:13866-71.

131. Barak N, Greenway FL, Fujioka K, Aronne LJ, Kushner RF. Effect of histaminergic manipulation on weight in obese adults: a randomized placebo controlled trial. Int $\mathrm{J}$ Obes (Lond). 2008;32:1559-65.

132. Guan X-M, Chen H, Dobbelaar PH, et al. Regulation of energy homeostasis by bombesin receptor subtype-3: selective receptor agonists for the treatment of obesity. Cell Metab. 2010;11:10112.

133. Banno R, Zimmer D, De Jonghe BC, et al. PTP1B and SHP2 in POMC neurons reciprocally regulate energy balance in mice. J Clin Investig. 2010;120:720-34.

134. Lantz KA, Hart SGE, Planey SL, et al. Inhibition of PTP1B by trodusquemine (MSI-1436) causes fat-specific weight loss in dietinduced obese mice. Obesity. 2010.

135. Roitman MF, Wescott S, Cone JJ, McLane MP, Wolfe HR. MSI-1436 reduces acute food intake without affecting dopamine transporter activity. Pharmacol Biochem Behav. 2010.

136. Tam S, Saiah E. Recent advances in the discovery and development of PTP-1B inhibitors. Drugs Future. 2008;33:175-85.

137. Tseng Y-H, Cypess AM, Kahn CR. Cellular bioenergetics as a target for obesity therapy. Nat Rev Drug Discov. 2010;9:465-82.

138. Cypess AM. Identification and importance of brown adipose tissue in adult humans. N Engl J Med. 2009;360:1509-17.

139. Marken Lichtenbelt WD. Cold-activated brown adipose tissue in healthy men. N Engl J Med. 2009;360:1500-8.
140. Virtanen KA. Functional brown adipose tissue in healthy adults. N Engl J Med. 2009;360:1518-25.

141. Arch JR. The discovery of drugs for obesity, the metabolic effects of leptin and variable receptor pharmacology: perspectives from $\hat{\mathrm{I}}^{2} 3$-adrenoceptor agonists. Naunyn-Schmiedeberg's Arch Pharmacol. 2008;378:225-40.

142. Frühbeck G, Becerril S, Sáinz N, Garrastachu P, García-Velloso MJ. BAT: a new target for human obesity? Trends Pharmacol Sci. 2009;30:387-96.

143. Larsen TM, Toubro S, Van Baak MA, et al. Effect of a 28-d treatment with L-796568, a novel $\beta 3$-adrenergic receptor agonist, on energy expenditure and body composition in obese men. Am J Clin Nutr. 2002;76:780-8.

144. Redman LM, De Jonge L, Fang X, et al. Lack of an effect of a novel $\beta 3$-adrenoceptor agonist, TAK-677, on energy metabolism in obese individuals: a double-blind, placebocontrolled randomized study. J Clin Endocrinol Metab. 2007; 92:527-31.

145. Bryzgalova G. Anti-obesity, anti-diabetic, and lipid lowering effects of the thyroid receptor $\beta$ subtype selective agonist KB141. J Steroid Biochem Mol Biol. 2008;111:262-7.

146. Scanlan TS. Sobetirome: a case history of bench-to-clinic drug discovery and development. Heart Fail Rev. 2010;15: $177-82$.

147. Villicev CM. Thyroid hormone receptor beta-specific agonist GC-1 increases energy expenditure and prevents fat-mass accumulation in rats. J Endocrinol. 2007;193:21-9.

148. Morton NM. Obesity and corticosteroids: 11 [beta]-Hydroxysteroid type 1 as a cause and therapeutic target in metabolic disease. Mol Cell Endocrinol. 2010;316:154-64.

149. Nawrocki AR, Scherer PE. Keynote review: the adipocyte as a drug discovery target. Drug Discov Today. 2005;10:121930 .

150. Wang M. Glucocorticoid antagonists and 11[beta]-HSD1 inhibitors. Drug Discov Today Ther Strat. 2007;4:117-22.

151. Wamil M, Seckl JR. Inhibition of 11ß-hydroxysteroid dehydrogenase type 1 as a promising therapeutic target. Drug Discov Today. 2007;12:504-20.

152. Gathercole LL, Stewart PM. Targeting the pre-receptor metabolism of cortisol as a novel therapy in obesity and diabetes. J Steroid Biochem Mol Biol. 2010 (In Press). doi:10.1016/j.j sbmb.2010.03.060.

153. Véniant MM, Hale G, Hungate RW, et al. Discovery of a potent, orally active $11 \hat{\mathrm{I}}^{2}$-hydroxysteroid dehydrogenase type 1 inhibitor for clinical study: identification of (S)-2-((1S, 2S, 4 R)-Bicyclo [2.2.1] heptan-2-ylamino)-5-isopropyl-5-methylthiazol-4 $(5 \mathrm{H})$-one (AMG 221). J Med Chem. 2010;53:4481-7.

154. Fotsch C, Wang M. Blockade of glucocorticoid excess at the tissue level: inhibitors of $11 \beta$-hydroxysteroid dehydrogenase type 1 as a therapy for type 2 diabetes. J Med Chem. 2008;51:48517.

155. Su X, Pradaux-Caggiano F, Thomas MP, et al. Discovery of adamantyl ethanone derivatives as potent $11 \beta$ - hydroxysteroid dehydrogenase type 1 (11ß-HSD1) inhibitors. ChemMedChem. 2010;5:1026-44.

156. Tiwari A. INCB-13739, an $11 \beta$-hydroxysteroid dehydrogenase type 1 inhibitor for the treatment of type 2 diabetes. IDrugs. 2010;13:266-75.

157. Baur JA. Biochemical effects of SIRT1 activators. Biochim Biophys Acta: Proteins Proteomics. 2010;1804:1626-34.

158. Jiang W-J. Sirtuins: novel targets for metabolic disease in drug development. Biochem Biophys Res Commun. 2008; 373:341-4.

159. Milne JC, Lambert PD, Schenk S, et al. Small molecule activators of SIRT1 as therapeutics for the treatment of type 2 diabetes. Nature. 2007;450:712-6. 
160. Bemis JE, Vu CB, Xie R, et al. Discovery of oxazolo[4, 5-b] pyridines and related heterocyclic analogs as novel SIRT1 activators. Bioorg Med Chem Lett. 2009;19:2350-3.

161. Feige JN. Specific SIRT1 activation mimics low energy levels and protects against diet-induced metabolic disorders by enhancing fat oxidation. Cell Metab. 2008;8:347-58.

162. Sitris Pharmaceuticals. Sirtris development pipeline. Accessed August 15th 2010. http://www.sirtrispharma.com/pipeline.html.

163. Pacholec M, Bleasdale JE, Chrunyk B, et al. SRT1720, SRT2183, SRT1460, and resveratrol are not direct activators of SIRT1. J Biol Chem. 2010;285:8340-51.

164. van Boekel G, Loves S, van Sorge A, Ruinemans-Koerts J, Rijnders $\mathrm{T}$, de Boer $\mathrm{H}$. Weight loss in obese men by caloric restriction and high-dose diazoxide-mediated insulin suppression. Diab Obes Metab. 2008;10:1195-203.

165. Due A, Flint A, Eriksen G, et al. No effect of inhibition of insulin secretion by diazoxide on weight loss in hyperinsulinaemic obese subjects during an 8-week weight-loss diet. Diab Obes Metab. 2007;9:566-74.

166. Rupnick MA, Panigrahy D, Zhang CY, et al. Adipose tissue mass can be regulated through the vasculature. Proc Natl Acad Sci USA. 2002;99:10730-5.
167. Cao Y. Adipose tissue angiogenesis as a therapeutic target for obesity and metabolic diseases. Nat Rev Drug Discov. 2010;9:107-15.

168. Reitman ML. Magic bullets melt fat. Nat Med. 2004;10:581-2.

169. Kolonin MG, Saha PK, Chan L, Pasqualini R, Arap W. Reversal of obesity by targeted ablation of adipose tissue. Nat Med. 2004;10:625-32.

170. Cao Y. Angiogenesis modulates adipogenesis and obesity. J Clin Invest. 2007;117:2362-8.

171. Tiwari A, Maiti P. TGR5: an emerging bile acid G-proteincoupled receptor target for the potential treatment of metabolic disorders. Drug Discov Today. 2009;14:523-30.

172. Watanabe M. Bile acids induce energy expenditure by promoting intracellular thyroid hormone activation. Nature. 2006;439:484-9.

173. Thomas C, Gioiello A, Noriega L, et al. TGR5-mediated bile acid sensing controls glucose homeostasis. Cell Metab. 2009;10:167-77.

174. Pellicciari R, Gioiello A, Macchiarulo A, et al. Discovery of $6 \alpha-$ ethyl-23(S)-methylcholic acid (S-EMCA, INT-777) as a potent and selective agonist for the TGR5 receptor, a novel target for diabesity. J Med Chem. 2009;52:7958-61. 